\title{
Water flow analysis and particle capture in ciliary suspension-feeding scallops (Pectinidae)
}

\author{
Hans Ulrik Riisgård ${ }^{1, *}$, Poul S. Larsen ${ }^{2}$ \\ ${ }^{1}$ Marine Biological Research Centre, University of Southern Denmark, Hindsholmvej 11, 5300 Kerteminde, Denmark \\ ${ }^{2}$ Department of Mechanical Engineering, Fluid Mechanical Section, Technical University of Denmark, Building 403, \\ 2800 Kgs. Lyngby, Denmark
}

\begin{abstract}
Gill structures in scallops were examined by scanning electron microscopy (SEM), and gill function and particle capture were studied by means of video-microscope observations and numerical calculations of flow patterns. Observations of particle movements were made on intact gills of Aequipecten opercularis (with the adductor muscle cut through) in order to map paths and speeds, and on isolated gill preparations (stimulated with serotonin [5-HT] to restore the activity of the water-pumping lateral cilia) in order to study cilia activity and interaction of particles with cilia. Video recordings of intact plicate gills of $A$. opercularis showed that particles approach the frontal side of the ordinary gill filaments at angles near $90^{\circ}$ and that particles may be deflected from the through flow to 'jump' down across these filaments towards the principal filament. Observations of isolated gill filaments indicate that the pro-laterofrontal cilia ahead of the water-pumping cilia may 'push' suspended particles, or fluid with particles, back against the current, either onto the frontal side of the filament, or out into the downward-directed water flow in the funnel between 2 crests. In order to set up a computational model to illustrate flow patterns, the volume flow rate through the interfilamental canals was estimated from experimentally determined filtration rates of undisturbed scallops. The filtration rate per $\mathrm{cm}$ lateral ciliary band was $\sim 0.25 \mathrm{ml} \mathrm{h}^{-1}$, implying a mean velocity in canals of $\sim 0.35 \mathrm{~mm} \mathrm{~s}^{-1}\left(5^{\circ} \mathrm{C}\right)$. Two-dimensional numerical flow calculations illustrate the global flow pattern in the funnel between 2 plicate gill crests, which show the contraction and acceleration of the central downflow towards the principal filament, while the inflow to the interfilament canals in the absence of pro-laterofrontal cilia is smoothly aligned at angles near $90^{\circ}$. However, when cilia are present, in various modes of simulated beat, local calculations show significant disturbances reaching well into the downflow. These results suggest potential flow-driven mechanisms responsible for transfer of particles to the frontal sides of ordinary filaments or into the main downward-directed flow between 2 plicate gill crests, contributing to the observed 'jumps'.
\end{abstract}

KEY WORDS: Video-microscope observations · Aequipecten opercularis · Effect of serotonin (5-HT) · Beat frequency of lateral cilia · Filtration rate $\cdot$ Particle-capture mechanism $\cdot$ Computational model Simulation of beating cilia

\section{INTRODUCTION}

A comprehensive body of literature deals with the function of the gill of ciliary suspension-feeding (or filterfeeding) bivalves. The traditional view has been that the feeding process results from the activities of the 3 main ciliary systems on the gill filaments: the lateral cilia pump water, the compound eu-laterofrontal cirri capture suspended food particles, and the frontal cilia transport captured particles away (Dral 1967). But the classical view has been questioned, mainly by fluid-mechanical arguments to the effect that currents generated by beating cilia contribute to the capture process, but also due to the fact that not all suspension-feeding bivalves possess eu-laterofrontal cirri (Jørgensen 1975, 1976, 1981, 1990, 1996, Owen \& McCrae 1976, Jørgensen et al. 
1984, Silvester \& Sleigh 1984, Nielsen et al. 1993, Riisgård et al. 1996, Ward 1996, Ward et al. 1998). This has led to speculation about the possible particle-capture mechanism in scallops and other bivalves which lack the cirri. In the present work, we focus on scallops, and as a way of presenting the problem, we begin with a minireview of the particle-capture mechanism in suspensionfeeding bivalves.

\section{Mini-review: particle-capture mechanisms in bivalves}

Suspension-feeding bivalves may have 2 types of laterofrontal tracts on the gills, namely compound eulaterofrontal cirri and/or rows of simple pro-laterofrontal cilia (Nelson 1960, Gibbons 1961, Owen 1974, Owen \& McCrae 1976). Both the eu-laterofrontal cirri and the pro-laterofrontal cilia may represent the basic arrangement of the laterofrontal tracts in the Bivalvia, but because the eu-laterofrontal cirri may have been lost in the families Pectinidae, Anomiidae and Pteriidae (Jørgensen 1976, Owen \& McCrae 1976), we use the term pro-laterofrontal cilia, as suggested by Owen \& McCrae (1976), although it literally means 'in front of the laterofrontal cilia'. The more logical term 'laterofrontal cilia' has been used by Beninger et al. (1988) to refer to the row of simple cilia between the lateral and the frontal cilia, but according to Owen \& McCrae (1976) the terms 'para-laterofrontal' (Nelson 1960, his Fig. 4), 'anomalous laterofrontal' and 'micro-laterofrontal cilia' should be dropped. Compound eu-laterofrontal cirri (henceforth 'laterofrontal cirri') are found in most suspension-feeding bivalves such as mussels, cockles, oysters, and clams, but not scallops (pectinids), Monia squama (Jørgensen et al. 1984), Anomia achaeus and Pteria macroptera (Jørgensen 1976).

Particle capture in bivalves with laterofrontal cirri

The so-called 'cirral particle-trapping mechanism' is believed to operate in suspension-feeding (or filterfeeding) bivalves with laterofrontal cirri (Nielsen et al. 1993, Riisgård et al. 1996, Riisgård \& Larsen 2001, but see Ward 1996, Ward et al. 1998). Here, bands of lateral cilia produce the main water transport through interfilamental canals of the gill. Near the entrance to the canals, particles are separated from the main current and transferred onto the frontal surface by the action of the laterofrontal cirri that have a fixed, alternating beat pattern. Riisgård et al. (1996) observed that food particles carried with the through current are stopped for a while at the entrance to the interfilament canal (or gap). Then the path is reversed $180^{\circ}$, and the particles are transferred to the frontal side of the gill filament to be transported toward the marginal food groove by frontal cilia. Transfer of particles is accomplished by the laterofrontal cirri or by the water currents they generate as they beat against the current through an angle of $90^{\circ}$. Particles $>4 \mu \mathrm{m}$ are stopped and transferred to the frontal side, whereas smaller particles either follow the flow around the cirri or are stopped by the cirri's branching cilia (Nielsen et al. 1993, Riisgård et al. 1996). On the basis of estimates of pressure drop for flow through a laterofrontal cirri screen and fluid-mechanical calculations of creeping flow, Riisgård et al. (1996) found it plausible that, during normal beating of the laterofrontal cirri, the through current passes mainly around the laterofrontal cirri and that only little flow may leak through the cilia branching off from the cirri shaft. It may be concluded that large particles $(>4 \mu \mathrm{m})$ are stopped and transferred to the frontal current, whereas smaller particles either follow the flow around the laterofrontal cirri and escape or are stopped by the branching cilia with or without physical contact (Silverman et al. 1996, 1999, Riisgård \& Larsen 2001). In mussels and other bivalves with compound laterofrontal cirri, particles $>4 \mu \mathrm{m}$ are retained with $100 \%$ efficiency by the gills (Møhlenberg \& Riisgård 1978, Jørgensen et al. 1984, Riisgård 1988).

\section{Scallops with pro-laterofrontal cilia}

The basic particle-capture mechanism in bivalves that only possess pro-laterofrontal cilia remains poorly understood (Owen \& McCrae 1976, Beninger et al. 1988, 1992, 2004, Silverman et al. 1995, 1996). According to Owen \& McCrae (1976) the laterofrontal tracts of the plicate gill of the scallop Chlamys varia consist of a single row of pro-laterofrontal cilia that are 12 to $15 \mu \mathrm{m}$ long and spaced 0.3 to $0.4 \mu \mathrm{m}$ apart and their effective beat is towards the frontal face of the filament.

Bivalve species that only possess pro-laterofrontal cilia are less efficient at retaining particles than species with lfc (Møhlenberg \& Riisgård 1978, Jørgensen et al. 1984, McHenery \& Birkbeck 1985, Riisgård 1988, Jørgensen 1990). The reported ability of the pectinids Aequipecten (Pecten) opercularis, Pseudamussium (Chlamys) septemradiatum (Møhlenberg \& Riisgård 1978) and Argopecten irradians (Riisgård 1988) to retain completely particles larger than $\sim 6 \mu \mathrm{m}$ in diameter makes it interesting to clarify if the pro-laterofrontal cilia play an active role in the retention of particles. However, according to Owen \& McCrae (1976) an examination of the plicate gill of Chlamys varia suggests that the collection of particles is dependent upon the flow of water currents rather than the direct filtration and transport of particles by cilia. Although some 


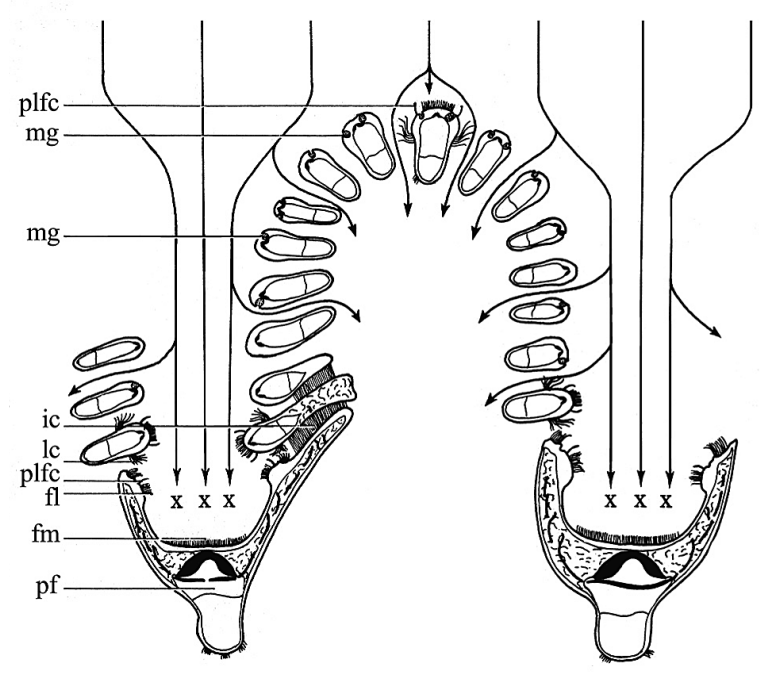

Fig. 1. Chlamys varia. Cross section of plicate gill lamella. Arrows indicate flow of water toward the gill surface and through the interfilamental canals; $\mathrm{x}$ indicates a dorsally directed flow in the gutters formed by the U-shaped principal filaments (pf). plfc: pro-laterofrontal cilia; mg: mucus gland; ic: interlocking cilia; lc: lateral cilia; fl: lateral tract of frontal cilia; $\mathrm{fm}=$ median tract of frontal cilia. From Owen \& McCrae (1976)

particles are captured on the frontal side of the gill filaments, most particles are caught up in the water currents flowing in the interplicate grooves (often referred to as 'troughs' in the literature) formed by the principal filaments, and the pro-laterofrontal cilia play no part in the process; rather the form of the plicae, the U-shaped principal filaments, and the flow of water created by the frontal cilia all combine to create 'a region of low pressure' which attracts particles into the grooves (Fig. 1).

Jørgensen (1981) made an attempt in qualitative terms to apply fluid-mechanical principles in interpreting particle movements in ciliary currents produced by the filibranch and the plicate bivalve gill. Jørgensen argued that in the gills of filibranch bivalves (e.g. Mytilus edulis) the single filament acts as the functional unit, but in the plicate gill it is the interplicate groove that constitutes the functional unit. Jørgensen suggested that particle drift in regions of strong velocity gradients may play an important role in preventing particles from escaping through the interfilamental canals. However, in a later paper Jørgensen (1983) stated that the model could not explain the efficiency of small-particle retention and instead suggested that oscillatory currents produced by the water-pumping lateral cilia may play an important role in the particle-capture mechanism (see also Jørgensen 1990).

The interpretation made by Owen \& McCrae (1976) of the mechanism of feeding and of ciliary currents was apparently in agreement with stereoscopic observations of living, non-narcotized specimens studied by Beninger et al. (1988). Further, Beninger et al. (1992) found that di- rect endoscopic observations of particles arriving at the scallop gill apparently confirmed in vivo the previously proposed mechanism of particle capture. The incurrent flow was observed to be parallel to the gill filaments (also reported by Ward et al. 1998), proceeding dorsally while being deflected into the interplicate grooves. This current appeared to be created by the ciliated frontal surfaces of the principal filaments and the lateral cilia of the ordinary filaments, and capture was suggested to be effected hydrodynamically by the currents produced by the frontal cilia on the principal filament. However, Ward et al. (1998) suggested that their use of video endoscopy had led to a new integrative explanation of particle capture in suspension-feeding bivalves based on hydrosol filtration theories. Thus, the observed low angle of particles approaching gill filaments should increase the probability of direct interception with frontal ciliary bands. Also, vortical flow patterns set up by prolaterofrontal cilia or laterofrontal cirri would reduce or block particle escape through interfilamental canals and promote particle retention on the frontal surface of filaments. The low angle of approach $\left(\sim 30^{\circ}\right)$ was not observed by Riisgård \& Larsen (2000) in their video-microscope observations of algal cells approaching the gill of an intact and actively feeding mussel, and their computed paths of particles for a model problem simulating the space between 2 demibranchs showed angles of approach near $90^{\circ}$. Other objections to the study by Ward et al. (1998), including insufficient optical resolution and image quality of endoscopy, have been advanced by Silverman et al. (2000) and Beninger (2000), but the question of vortical flows near the entrance to the interfilamental canal (Ward et al. 1998) appears not to have been resolved. Thus, while the particle-capture mechanism and streamline pattern of the flat mussel gill seem to be rather well understood (cf. Beninger 2000, Riisgård \& Larsen 2000, 2001, Silverman et al. 2000, but see Ward et al. 1998, 2000), the particle-capture mechanism in the plicate pectinid gill is incompletely understood.

\section{Purpose of present work}

The objectives of this study were to refine what we know about the plicate pectinid gill by contributing new observations and numerical calculations of flow patterns. Gill structures were examined by scanning electron microscopy (SEM), and video-microscope observations of particle movements were made on the gills of living scallops and on gill preparations. In doing so, we also examined the effect of serotonin $(5-\mathrm{HT})$ on the beat frequency of the lateral cilia, experimentally determined the filtration rates of intact, undisturbed scallops, and measured the total length of the water-pumping lateral ciliary band on the gill. 


\section{MATERIALS AND METHODS}

SEM observations. The structure of the ciliary systems was studied on scanning electron micrographs (SEM) of gill fragments dissected out of small specimens of Palliolium furtivum (Lovén) (Pecten furtivus) and Aequipecten opercularis (Linnaeus) (Pecten opercularis), obtained from the Marine Biological Laboratory, Helsingør (Denmark), quick-frozen by liquid $\mathrm{N}_{2}$ $\left(-210^{\circ} \mathrm{C}\right.$, in an attempt to preserve ciliary metachronic waves) and subsequently fixed in $2 \% \mathrm{OsO}_{4}$, and further prepared according to the freeze-drying technique described by Nørrevang \& Wingstrand (1970).

Video observations. All video observations were made at the Marine Biological Research Centre, Kerteminde (Denmark) on scallops Aequipecten opercularis obtained from the public aquarium at Marine Biological Laboratory, Helsingør. The scallops were kept in aerated seawater $\left(\sim 15^{\circ} \mathrm{C}\right)$ until video-microscope recordings could be made at room temperature $\left(\sim 20^{\circ} \mathrm{C}\right)$.

Low magnification: Paths of carmine particles $(<40 \mu \mathrm{m})$ approaching the gill surface of Aequipecten opercularis (with the adductor muscle cut through to prevent closure of the valves and to ensure sufficient light) were recorded using a video camera attached to a horizontal dissecting microscope (Wild M3C) placed in front of a bivalve observation chamber holding an actively feeding scallop. The main purpose of these video recordings was to trace the path and measure the speed of particles approaching the gill surface in order to compare the experimentally observed values to computed velocities of water flowing into the funnel between 2 plicate gill crests. All observations were made on the posterior tip of a demibranch which in $A$. opercularis may stick out somewhat freely in the surrounding water just in front of the exhalant opening. Attempts to make video-microscope recordings of gill tips of undisturbed scallops failed due to frequent closure of the valves, and therefore the adductor muscle was cut through. However, this apparently did not seriously disturb either the geometry of the plicate gill tip or, judging from the ability of the gill tip to pump water and at the same time capture suspended particles, the normal function of the free anterior tip of the demibranch.

High magnification: Paths of algal cells were studied using the observation vessel submerged microscope objective technique previously used by Nielsen et al. (1993) and Riisgård et al. (1996, their Fig. 1). Gill-filament preparations were isolated in an approximately $10 \times 10 \mathrm{~cm}$ temperature-controlled $\left(16.8^{\circ} \mathrm{C}\right)$ microscope observation vessel filled with seawater to a level of $2 \mathrm{~cm}$. The gill preparations were fixed $1 \mathrm{~cm}$ above the bottom by means of clips attached to 2 movable (rotational and translational) rods, leaving approxi- mately $1 \mathrm{~cm}$ of seawater above the free surface of the gill filaments. The vessel was placed on a microscope stage (Nikon with depth of focus of $60 \mu \mathrm{m}$ at $40 \times$ magnification) with the cross-table removed so that the microscope objective could be immersed in the water above the gill preparation, which was illuminated through a thin glass window in the bottom of the chamber. The objective was far enough (6 to $7 \mathrm{~mm}$ ) from the gill filaments not to affect the rate and direction of flows. A suspension of flagellate cells (Rhodomonas sp., almost spherical, diameter $=$ ca. $6.2 \mu \mathrm{m}$ ) was added to the seawater to study particle behaviour and to measure the velocity of particles approaching and passing single isolated gill filaments.

Particle paths and velocities were observed and recorded using a video camera (Kappa CF 11/1) attached to the microscope, and a 50 half-frames-per-second video recorder (Panasonic NV-FS200 HQ). Video frames were copied to paper by means of a video graphic printer (Sony UP-860 CE). Relative movements of the particles were traced from their position in successive frames, usually with time intervals of $0.2 \mathrm{~s}$.

The metachronal waves of lateral cilia, moving in opposite directions on 2 adjacent filaments, could be seen and quantified. The wavelength $(\lambda, \mu \mathrm{m})$ was determined as the distance between 2 wave crests; the wave speed $\left(C, \mu \mathrm{m} \mathrm{s}^{-1}\right)$ was estimated on the basis of the distance a wave crest had moved during $0.2 \mathrm{~s}$ (10 half-frames), and subsequently the lateral cilia beat frequency was estimated as: $f=c / \lambda$ using mean values of 8 determinations of both wavelength and wave speed.

In suspension-feeding bivalves, serotonin (5-hydroxytryptamine $=5-\mathrm{HT}$ ) is known to act in a cilio-excitatory way (Aiello 1960, Jørgensen 1975), and in isolated gill preparations, the frequency of beating soon decreases and the activity becomes unstable (Jørgensen 1976). Addition of 5-HT, however, restores rapid and stable beating of the lateral cilia in mussels (Nielsen et al. 1993, Riisgård et al. 1996), but hitherto the effect of 5-HT has not been thoroughly studied in scallops. In the present work the effect of 5-HT on the beat frequency of the lateral cilia was therefore studied in more detail by adding $10^{-7}, 10^{-6}, 5 \times 10^{-6}, 10^{-5}$, and $5 \times$ $10^{-5} \mathrm{M} 5$-HT to the microscope observation vessel in order to identify the concentration of 5-HT which optimally stimulates the ciliary beat frequency to ensure that about normal water velocities in dissected gill filaments could be re-established.

Filtration rates. Specimens of Aequipecten opercularis were collected in February 2004 at $40 \mathrm{~m}$ water depth $\left(3.9^{\circ} \mathrm{C}, 30 \% \mathrm{~S}\right)$ in the northern part of Øresund, Denmark, by the Marine Biological Laboratory in Helsingør, and brought to the Marine Biological Research Centre in Kerteminde, where measurement of the fil- 
tration rate was made soon after $\left(5\right.$ or $\left.7^{\circ} \mathrm{C}, 30 \% \mathrm{~S}\right)$. The main purpose was to measure filtration rates of intact, undisturbed scallops so that, when the total length of the water-pumping lateral ciliary band on the gill was known, the water velocity in the interfilamental canals could be established and subsequently used as an important parameter in the numerical calculations of flow patterns.

The filtration rate $(F)$ was measured as the volume of water cleared of suspended particles per unit of time in an aquarium with either a group of 5 scallops or a single scallop and well-mixed seawater with added algal cells (Rhodomonas sp.). The reduction in the number of particles as a function of time was recorded by taking water samples at fixed time intervals and measuring the particle concentration with an electronic particle counter (Elzone 5380 with a $76 \mu \mathrm{m}$ orifice tube). The clearance rate $(\mathrm{Cl})$ was determined from the exponential decrease, e.g. verified as a straight line in a semilog plot in algal concentration as a function of time using the formula: $\mathrm{Cl}=\mathrm{Va} / \mathrm{n}$, where $\mathrm{V}=$ volume of water $(4 \mathrm{l}), \mathrm{n}=$ number of actively filter-feeding individuals, and $a=$ slope of regression line in a semi-ln plot for the reduction in algal concentration with time in the aquarium. A control experiment (without scallops) showed that no significant sedimentation of algal cells took place during a period of $2 \mathrm{~h}$. The fact that the suspended algal cells are $100 \%$ efficiently retained by the gills of undisturbed and non-satiated Aequipecten opercularis (Møhlenberg \& Riisgård 1978) implies that $C l=F$ (true filtration rate $=$ pumping rate).

\section{RESULTS}

\section{SEM and video observations}

Fig. 2 shows frontal side SEM pictures of a quickfrozen scallop gill composed of filaments with tracts of lateral cilia organized in 'frozen' metachronic waves, and a row of pro-laterofrontal cilia between the lateral and frontal cilia.

Apparently, the cutting of the adductor mussel did not seriously disturb either the geometry of the gill tip observed or its ability to function normally, judging from the ability of the gill tip to pump water and at the same time capture suspended particles. The videomicroscope recordings show that particles captured on the frontal side of the ordinary gill filaments may be transported a short distance on the frontal side before the particles 'jump' across the ordinary filaments in a downward direction to eventually land on the principal filament to be carried away via the dorsal groove towards the mouth (Fig. 3). The paths and velocities of particles approaching the gill surface are shown in
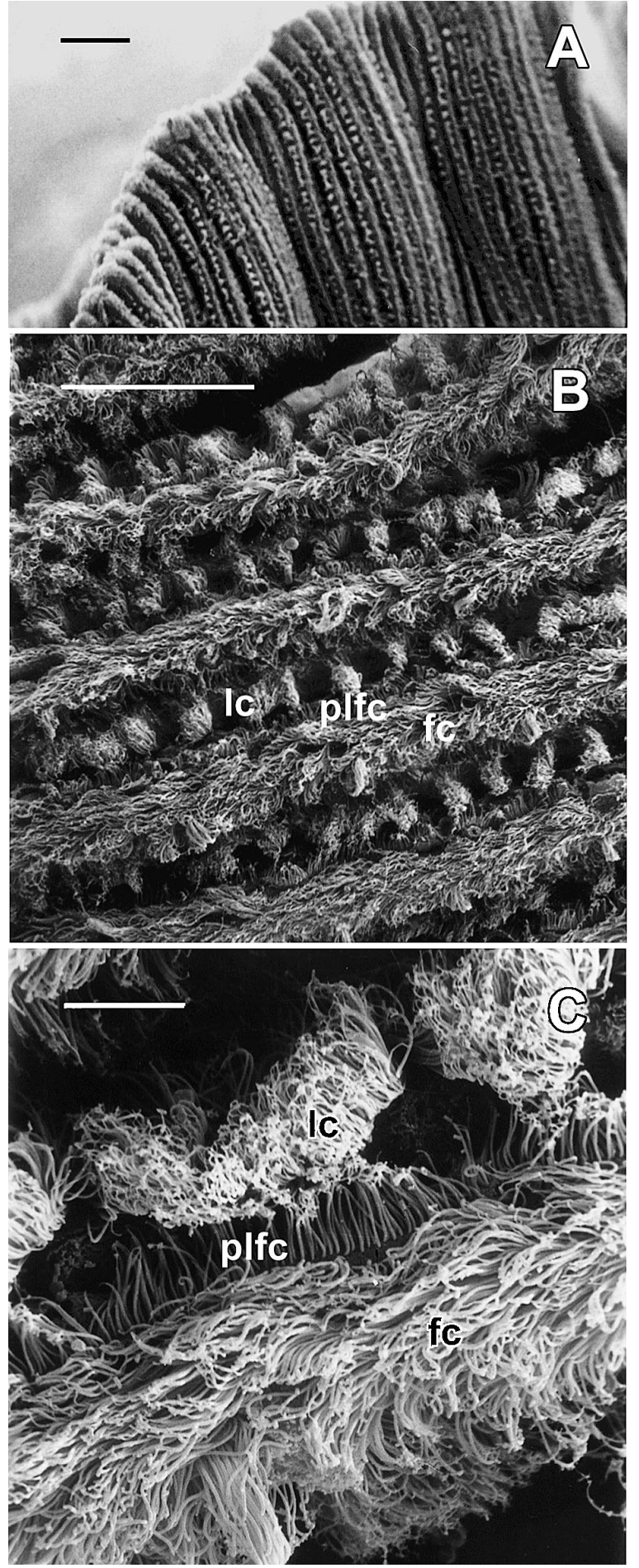

Fig. 2. Palliolium (Pecten) furtivum. Scanning electron microscope (SEM) pictures of frontal side of quick-freezed gill composed of filaments with ciliary tracts. (A) Part of gill showing ventral bend and 3 crests composed of ordinary filaments. Scale bar $=100 \mu \mathrm{m}$. (B) Filaments separated by interfilamental gaps with lateral cilia (lc) organized in 'frozen' metachronic waves. Scale bar $=100 \mu \mathrm{m}$. plfc: pro-laterofrontal cilia; fc: frontal cilia. (C) Close-up of a small part of filament with a row of plfc clearly seen between lc and fc. Scale bar $=20 \mu \mathrm{m}$ 
A

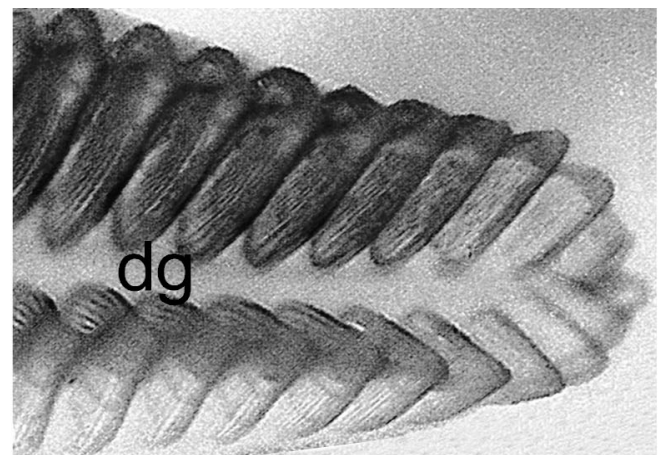

B
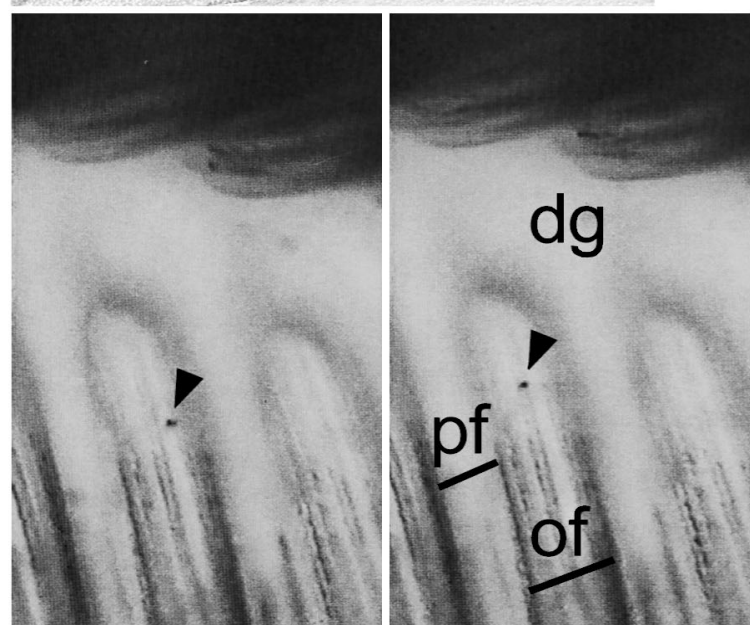

Figs. 4 \& 5. The particle paths are always curved in the direction normal to the gill frontal surface previous to capture. Particles entering the funnel between 2 plicate gill crests are seen to be accelerated to gain a maximum speed of $\sim 1.5 \mathrm{~mm} \mathrm{~s}^{-1}$.

When the lateral cilia are beating, the pro-laterofrontal cilia cannot be distinguished. However, in isolated gill
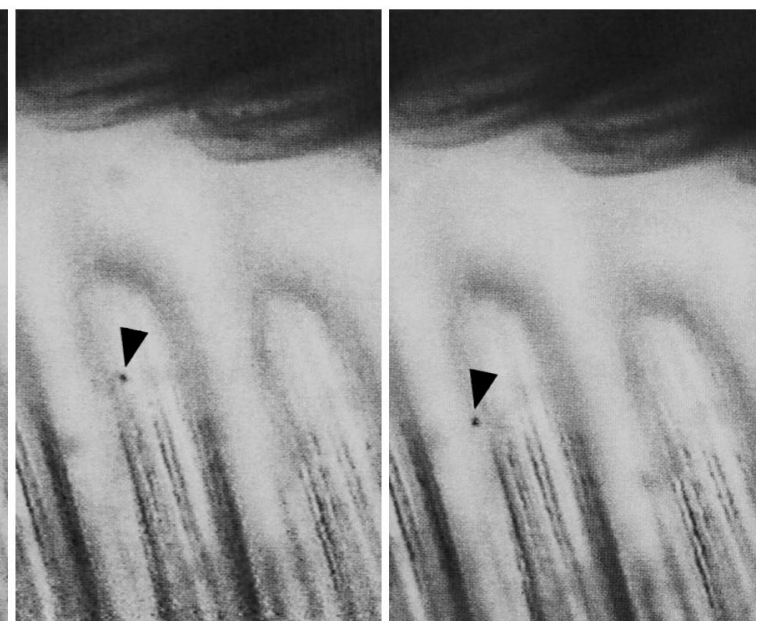

Fig. 3. Aequipecten opercularis. (A) Posterior tip of a demibranch with dorsal groove (dg). (B) Infrabranchial surface of gill arch with plicate gill crests composed of ordinary filaments (of) and interplicate grooves that open into the dorsal groove (dg) that transports captured particles in a slurry to the left (i.e. anterioward toward the mouth). The 4 video graphic pictures show a particle (arrowheads) being transported from the frontal side of a gill filament on the plicate gill crest through a series of 'jumps' (right to left) down onto the frontal surface of a principal filament (pf) at the bottom of the crest funnel. Time between pictures $=0.2 \mathrm{~s}$

filaments it was found that the frequency of beating of the lateral cilia decreased soon after preparation. In this situation the sporadic active pro-laterofrontal cilia could be seen above the band of inactive lateral cilia, and in some instances suspended algal cells were seen to be transferred or 'pushed' by the pro-laterofrontal cilia from the entrance to the interfilamental canal onto
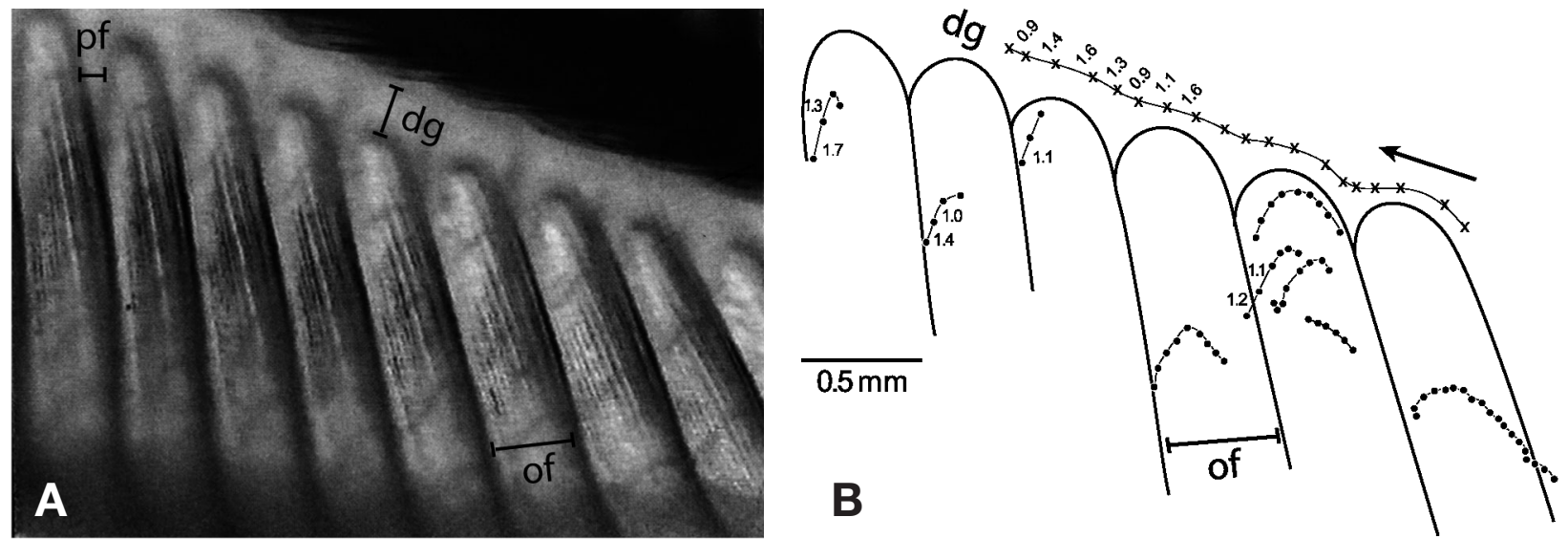

Fig. 4. Aequipecten opercularis. (A) Video graphic print of plicate gill (of: ordinary filaments; pf: principal filament) and dorsal groove (dg). (B) Paths of free suspended particles $(\bullet)$ approaching the gill surface from the right are shown together with an example of a captured particle (x) being transported to the left in the dorsal groove. Time interval between each dot or cross symbolizing an article is $0.1 \mathrm{~s}$. Estimated velocity $\left(\mathrm{mm} \mathrm{s}^{-1}\right)$ is indicated. (Note: A video clip related to Fig. 4 has been placed on the MEPS web page as supplementary material, available at: www.int-res.com/articles/suppl/m303p177_video.wmv) 

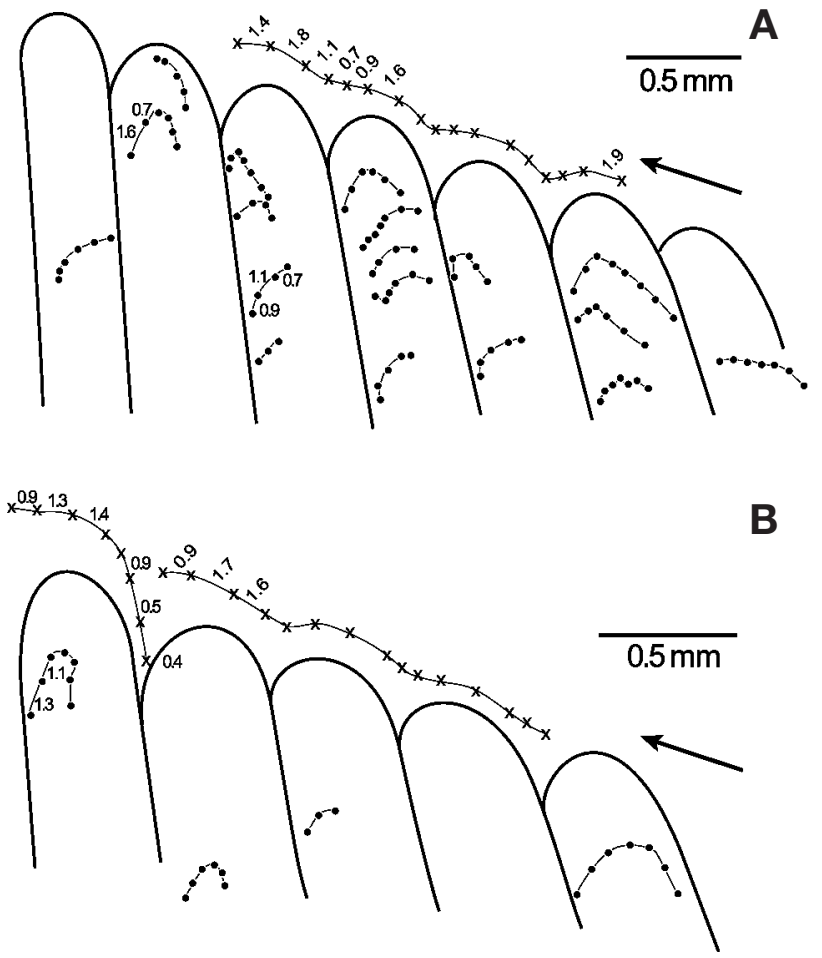

Fig. 5. Aequipecten opercularis. Paths of suspended particles approaching the gill surface $(\bullet)$ and captured particles $(\mathbf{x})$ transported in the dorsal groove obtained by means of video recording 2 sequences, (A) and (B), are shown. Suspended particles come from the right and move downward towards the gill surface, whereas captured particles in the groove move from right to left. Time interval between each dot or cross symbolizing a particle is $0.1 \mathrm{~s}$. Estimated velocity $\left(\mathrm{mm} \mathrm{s}^{-1}\right)$ is indicated

the frontal side of the filament (in $~ 0.02$ to $0.04 \mathrm{~s}$ ) and subsequently carried away by the frontal cilia (Fig. 6). This observation is likely to reflect elements of the natural particle-capture process.

The cilio-excitatory effect of 5 -HT on isolated gill filaments is depicted in Fig. 7. It is seen that the beat frequency (wavelength and wave speed) of the lateral cilia increases from $f=10.6 \pm 0.6 \mathrm{~Hz}(\lambda=10 \mu \mathrm{m}, c=$ $106 \mathrm{\mu m} \mathrm{s}^{-1}$ ) without 5 -HT in the surrounding water to $13.1 \pm 0.4 \mathrm{~Hz}\left(10 \mu \mathrm{m}, 131 \mu \mathrm{m} \mathrm{s}^{-1}\right), 14.9 \pm 0.7 \mathrm{~Hz}(11$ $\left.\mu \mathrm{m}, 164 \mu \mathrm{m} \mathrm{s}^{-1}\right), 17.8 \pm 0.4 \mathrm{~Hz}\left(10.6 \mu \mathrm{m}, 189 \mu \mathrm{m} \mathrm{s}^{-1}\right)$, $19.5 \pm 0.8 \mathrm{~Hz}\left(7.9 \mu \mathrm{m}, 154 \mu \mathrm{m} \mathrm{s}^{-1}\right)$ and $22.7 \pm 1.8 \mathrm{~Hz}$ $\left(6.7 \mu \mathrm{m}, 149 \mu \mathrm{m} \mathrm{s}^{-1}\right)$, with final concentrations of $10^{-7}$, $10^{-6}, 5 \times 10^{-6}, 10^{-5}$, and $5 \times 10^{-5} \mathrm{M}$ in the microscope observation vessel, respectively. At the physiologically unrealistically high concentration of $10^{-4} \mathrm{M}$ 5-HT (Jørgensen 1975), the beat frequency decreased to $18 \mathrm{~Hz}$. It may be concluded that 5 -HT is highly potent in stimulating the activity of the lateral cilia on the gill filaments of Aequipecten opercularis and probably other pectinids when the substance is added to the surrounding water.
In cases where isolated gill filaments were exposed to $10^{-5} \mathrm{M} 5$-HT to restore the lateral ciliary activity, the movement of particles past the lateral side of the filament was video recorded (Figs. 8 \& 9). It is seen that the particles are being accelerated up to a speed of ca. 1 to $1.3 \mathrm{~mm} \mathrm{~s}^{-1}$, depending on position above the band of lateral cilia. In some cases the particles seem to be influenced by the ciliary recovery. Based on these observations, it seems likely that the approx. 12 to $15 \mu \mathrm{m}$ long pro-laterofrontal cilia beating against the interfilamental through-current may hit or move fluid with the suspended particles and thus 'push' the particles back against the current, either onto the frontal side of the filament or apparently more frequently out into the downward-directed water flow in the funnel between 2 plicate gill crests. When a particle is being sucked into the entrance to the interfilamental canal and repeatedly pushed back into the downward intercrest funnel flow, this resembles a series of 'jumps' downward from the top of the crest to the principal filament at the bottom.

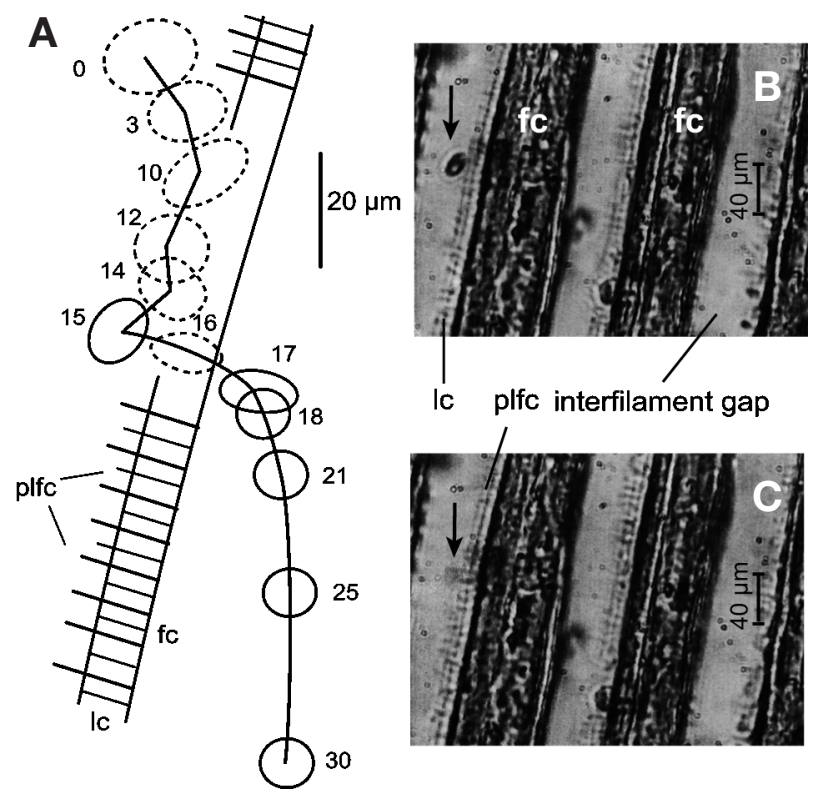

Fig. 6. Aequipecten opercularis. (A) Gill filament, only leftside boundary indicated, in which a particle (Rhodomonas sp. algal cell) is transferred from the entrance of the interfilament canal (frame 0 to 15 ) to the band of frontal cilia (fc) (frame 17 to 30 ) by the pro-laterofrontal cilia (plfc), which are seen above a band of inactive lateral cilia (lc) (because no serotonin [5-HT] has been added to the surrounding water). Time interval between circles symbolizing particles is expressed in number of video frames from the start at 0 (time interval between frames $=0.02 \mathrm{~s}$ ). Particles seen in focus on the microscope video recordings are indicated by unbroken circles; blurred particles partly out of focus are indicated by broken circles. (Right) Video graphic picture of frame (A) 15 and (B) 16 showing capture of algal cell (arrow) as indicated 


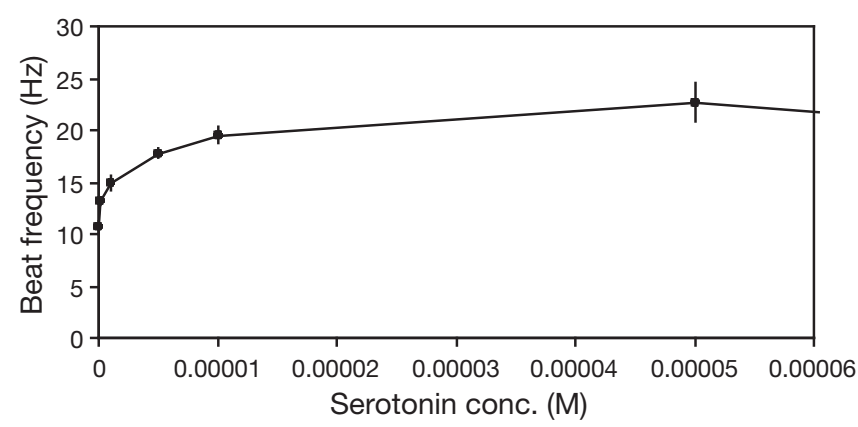

Fig. 7. Pecten opercularis. Beat frequency of lateral cilia (mean $\pm \mathrm{SD}, \mathrm{n}=8$ ) in isolated gill filaments as a function of serotonin concentration at $16.8^{\circ} \mathrm{C}$. The value for $10^{-4} \mathrm{M} 5$-HT is not shown

\section{Filtration rates}

Figs. $10 \& 11$ show examples of filtration rate measurement in Aequipecten opercularis. In a group of 5 scallops (Group 1), the maximum filtration rate was obtained after $2 \mathrm{~h}$ (Fig. 10). Likewise the maximum filtration rate in Group 2 was obtained $\sim 2 \mathrm{~h}$ after the first addition of algal suspension (Fig. 11A) whereas the maximum filtration rate was attained as early as $\sim 0.5 \mathrm{~h}$ after the first addition of algal suspension in Group 3 (Fig. 11B). Filtration rates measured on single individuals were higher than those on a group of scallops because not all individuals in a group may be fully open after the initial stimulation period following the first algal addition, and because shell clattering by some of the individuals in a group may disturb the other scallops, leading to reduced opening degree and subsequently reduced filtration rate.

The maximum filtration rate $(F)$ measured in the scallops is shown in Table 1 along with the estimated filtration rate per $\mathrm{cm}$ lateral ciliary band $\left(F_{\mathrm{lc}}\right)$. The total length of the lateral ciliary band $\left(T_{\mathrm{lc}}\right)$ was estimated by multiplying the number of gill filaments with the measured length of the filaments, which was then multiplied by 2 because there is 1 lateral ciliary band on

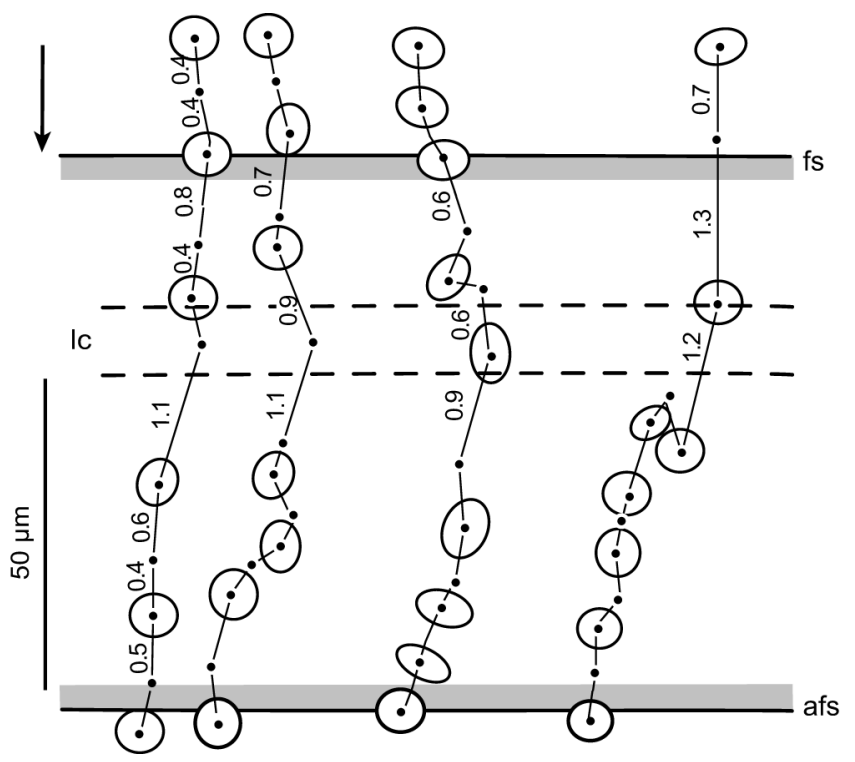

Fig. 8. Aequipecten opercularis. Lateral view of isolated 5-HT stimulated $\left(10^{-5} \mathrm{M}\right)$ gill filament showing particles (Rhodomonas sp. algal cells) being accelerated by the water-pumping lateral ciliary band (lc) from the frontal side (fs) down to the abfrontal side (afs) of the gill filament. Time interval is $0.02 \mathrm{~s}$ between position of particles shown (indicated by dots and contour of algal cells at every second position observed. Estimated velocity $\left(\mathrm{mm} \mathrm{s}^{-1}\right)$ is indicated

each lateral side of a filament. The gill consists of $2 \mathrm{~W}$ shaped demibranchs comprising 8 gill lamella, 4 of which are somewhat shorter than the other 4 . In the scallop in Group 4 (Table 1), the total number of counted filaments per lamella was 3120 and the number of crests 195, each consisting of $16 \pm 1.2$ filaments (including the principal filament). Using each of the 2 demibranchs in the scallop in Group 4 (treated with $7.5 \% \mathrm{MgCl}_{2}$ to relax muscles and avoid contractions), 2 estimates of the total length of the lateral ciliary band were 55798 and $58968 \mathrm{~cm}$, respectively. The mean value of $57400 \mathrm{~cm}$ was used for estimating the filtration rate per $\mathrm{cm}$ lateral ciliary band in Table 1.

Table 1. Aequipecten opercularis. Shell length $(L)$, shell breadth $(B)$, wet wt $\left(W_{\mathrm{w}}\right)$ and dry wt ( $\left.W_{\mathrm{d}}\right)$ of soft parts of 1 group of $5 \mathrm{scal}-$ lops (Group 1) and 2 individual scallops used for measurement of filtration rate (Groups 2 and 3). Maximum individual filtration rates $(F)$ measured at 5 and $7^{\circ} \mathrm{C}$ are shown along with the estimated filtration rate $\left(F_{\mathrm{lc}}\right)$ for Scallop 4 which was used for measurement of total length of the lateral ciliary band $\left(T_{\mathrm{lc}}=57400 \mathrm{~cm}\right.$ used in all cases). Finally, the estimated filtration rate per $\mathrm{cm}$ lateral ciliary band $\left(F_{\mathrm{lc}}=T_{\mathrm{lc}} / F\right)$ at 5 and $7^{\circ} \mathrm{C}$ are shown

\begin{tabular}{|c|c|c|c|c|c|c|c|c|c|}
\hline $\begin{array}{l}\text { Scallop } \\
\text { group }\end{array}$ & (n) & $\begin{array}{c}L \\
(\mathrm{~mm})\end{array}$ & $\begin{array}{c}B \\
(\mathrm{~mm})\end{array}$ & $\begin{array}{l}W_{\mathrm{w}} \\
(\mathrm{g})\end{array}$ & $\begin{array}{l}W_{\mathrm{d}} \\
(\mathrm{g})\end{array}$ & $\begin{array}{c}F \\
\left(1 \mathrm{~h}^{-1}\right) \\
5^{\circ} \mathrm{C}\end{array}$ & $\begin{array}{c}F \\
\left(1 \mathrm{~h}^{-1}\right) \\
7^{\circ} \mathrm{C}\end{array}$ & $\begin{array}{c}F_{\mathrm{lc}} \\
\left(\mathrm{ml} \mathrm{h}^{-1} \mathrm{~cm}^{-1}\right) \\
5^{\circ} \mathrm{C}\end{array}$ & $\begin{array}{c}F_{\mathrm{lc}} \\
\left(\mathrm{ml} \mathrm{h}^{-1} \mathrm{~cm}^{-1}\right) \\
7^{\circ} \mathrm{C}\end{array}$ \\
\hline 1 & 5 & $65.2 \pm 3.5$ & $68.4 \pm 3.7$ & $8.85 \pm 1.00$ & $1.278 \pm 0.151$ & & 8.3 & & 0.15 \\
\hline 2 & 1 & 54.1 & 55.2 & 5.69 & 0.783 & 9.5 & 6.7 & 0.17 & 0.12 \\
\hline 3 & 1 & 73.0 & 77.1 & 14.19 & 1.695 & 13.7 & 15.0 & 0.24 & 0.26 \\
\hline 4 & 1 & 62.8 & 65.5 & & & $11.4^{\mathrm{a}}$ & & 0.20 & \\
\hline
\end{tabular}




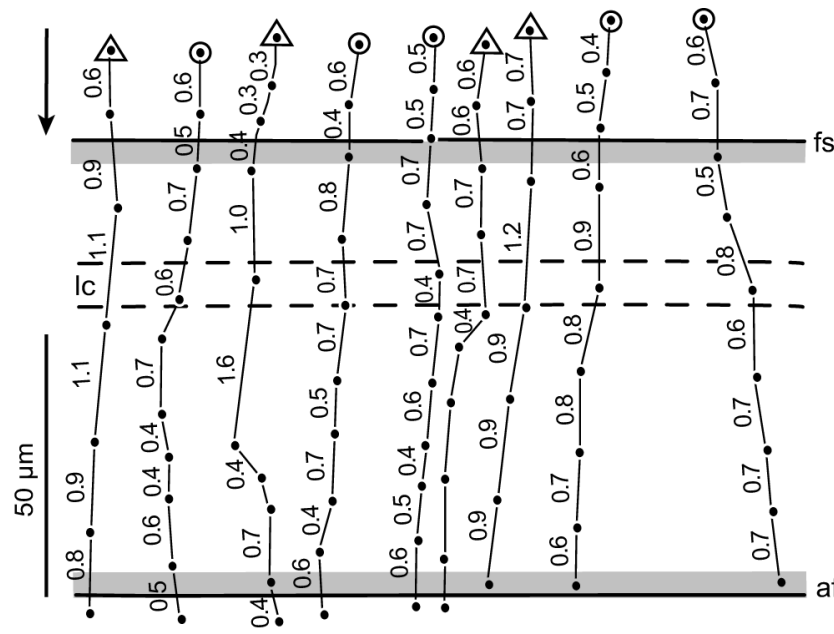

Fig. 9. Aequipecten opercularis. Lateral view of isolated 5-HT stimulated $\left(10^{-5} \mathrm{M}\right)$ gill filament showing particles (Rhodomonas sp. algal cells) being accelerated by the water-pumping lateral ciliary band (lc) from the frontal side (fs) down to the abfrontal side (afs) of the gill filament. The time interval between dots symbolizing particles is $0.02 \mathrm{~s}$. Particles seen in focus on the microscope video recordings (i.e. close to the lateral surface of the gill filaments) are indicated by circles; blurred particles partly out of focus (i.e. relatively far off from the lateral surface of the gill filament) are indicated by triangles. Estimated velocity $\left(\mathrm{mm} \mathrm{s}^{-1}\right)$ is indicated

The value $F_{\text {lc }}$ shown in Table 1 can be used to estimate the water velocity in the interfilamental canals of $40 \mu \mathrm{m}$ width $L_{i}(=0.004 \mathrm{~cm}$, obtained from video-microscope recordings of an intact gill) as $U_{i}=Q / A$, where $Q=$ volume flow of $2 \times F_{\text {lc }}$ per cm interfilament canal and $A=$ interfilamental suction area per $\mathrm{cm}(=4 \times$ $10^{-3} \mathrm{~cm}^{2}$ ). In the present work on flow analysis (next section), a value of $F_{\mathrm{lc}}=0.25 \mathrm{ml} \mathrm{h}^{-1} \mathrm{~cm}^{-1}$ is used (scallop in Group 3 in Table 1), which implies that the mean velocity in the interfilamental canals is $U_{i}=2 \times 0.25$ / $4 \times 10^{-3}=125 \mathrm{~cm} \mathrm{~h}^{-1}=0.35 \mathrm{~mm} \mathrm{~s}^{-1}$.

\section{Flow analysis}

To help understand the process of particle capture, numerical flow calculations were made both for the global flow between 2 plicate gill crests and for the local flow into interfilamental canals with and without the simulated effect of moving pro-laterofrontal cilia. The computational models employ the vorticity-stream function formulation in the creeping-flow limit of vanishing Reynolds numbers. This formulation is convenient for an incompressible, 2-dimensional flow for which-as here-values of the stream function (volume flow per unit depth) may be specified along boundaries (see Appendix 1 for details).

First, to illustrate the flow pattern in a cross section of the funnel between 2 plicate gill crests composed of
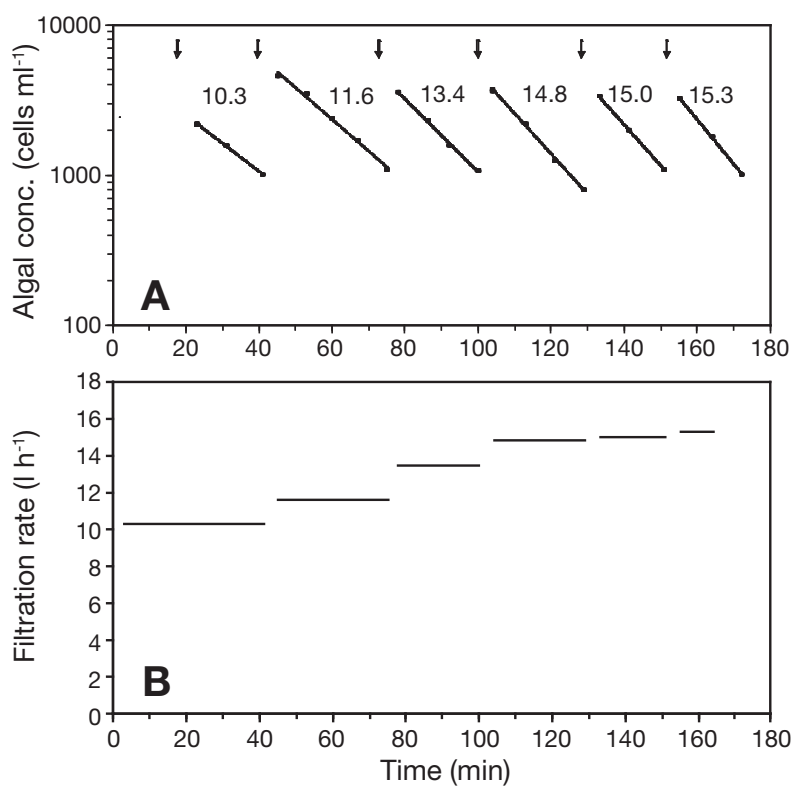

Fig. 10. Aequipecten opercularis. (A) Exponential reduction in algal cell concentration due to grazing by a group of 5 scallops (Group 1 in Table 1) in a closed system with well-mixed water. Arrows indicate additions of new algal suspension. Regression lines and the estimated filtration rates $\left(\mathrm{h} \mathrm{h}^{-1}\right.$ ind. $\left.{ }^{-1}\right)$ are indicated. (B) Estimated filtration rate as a function of time after first algal addition. Maximum filtration rate was obtained ca. $2 \mathrm{~h}$ after the first addition of algal suspension
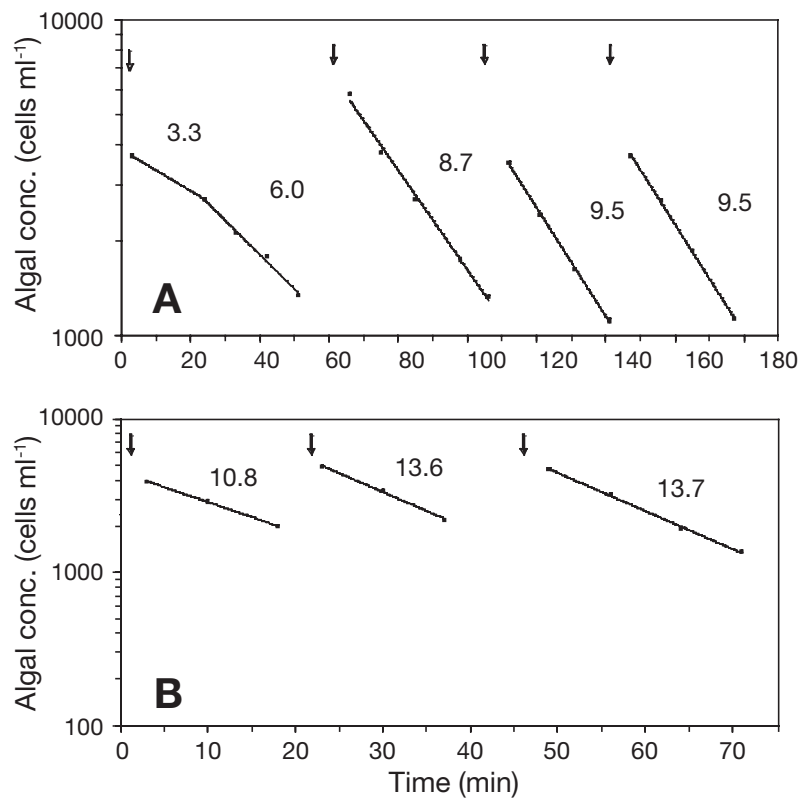

Fig. 11. Aequipecten opercularis. Exponential reduction in algal cell concentration due to grazing by scallops in a closed system with well-mixed water. Arrows indicate additions of new algal suspension. Regression lines and estimated filtration rates $\left(\mathrm{l} \mathrm{h}^{-1}\right)$ are indicated. (A) Scallop in Group 2 (Table 1); maximum filtration rate was obtained ca. $2 \mathrm{~h}$ after the first addition of algal suspension. (B) Scallop in Group 3 (Table 1); maximum filtration rate was obtained ca. $0.5 \mathrm{~h}$ after the first addition of algal suspension 
ordinary gill filaments, we consider the geometry of Chlamys varia (Fig. 1). To specify appropriate boundary conditions, we are aided by the present videomicroscope observations, which provide paths and velocities of particles approaching the gill surface as well as velocities of captured particles transported in the grooves (Figs. $4 \& 5$ ). These data, along with experimentally determined volume flow rates through the interfilamental canals (Table 1) and known morphological dimensions, are used along with the requirement of overall mass conservation.

Consider one-half of the cross section, bounded by lines of symmetry, as shown in Fig. 12. The flow into this domain from above is driven by the lateral cilia pumps in the interfilamental canals and by the cilia on the frontal side of the principal filament. As shown in the previous section, the mean velocity is estimated to be $U_{i} \approx 0.35 \mathrm{~mm} \mathrm{~s}^{-1}$ in the $L_{i}=0.040 \mathrm{~mm}$ wide canals, hence the volume flow per $1 \mathrm{~mm}$ 'slice' (or unit depth, D) $D$ becomes $Q_{i}=U_{i} L_{i} D \approx 0.35 \times 0.040 \times 1=0.014 \mathrm{~mm}^{3}$ $\mathrm{s}^{-1}$ to each of 7 interfilamental canals. A single measurement in Fig. 5 (B) (and other measurements not shown) suggests that the velocity $U_{1}$ of the dorsally directed flow in the groove formed by the U-shaped principal filament is $\sim 0.4 \mathrm{~mm} \mathrm{~s}^{-1}$ (which is 3 to 4 times lower than the flow velocity in the dorsal groove). The

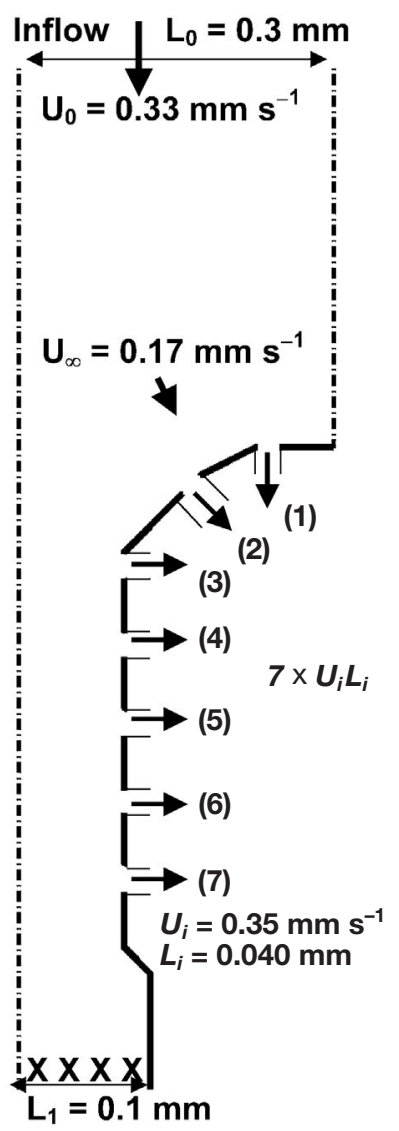

Fig. 12. Computational domain of one-half of the cross section of interplicate groove of Chlamys varia. Uniform inflow (top) driven by the outflow through 7 interfilamental canals (labeled 1 to 7 ) and by the small ( 0.8\%) flow in the principal filament $(\mathbf{X} \mathbf{X} \mathbf{X})$. Lines of symmetry (--ne). $L_{0}$ : half width of groove; $U_{0}$ : inflow velocity; $U_{\infty}$ : velocity upstream of interfilamental canals; $U_{i}$ : mean velocity in the interfilamental canals; $L_{\mathrm{i}}$ : width of interfilamental canals; $L_{1}$ : half width of principal filament groove thickness $L_{2}$ of the stream in the principal filament groove is not known, but $25 \%$ of $L_{1}=0.02 \mathrm{~mm}$ may be suggested. An estimate of the volume flow in the principal filament groove may thus be found to be $Q_{1}=$ $U_{1} L_{1} L_{2} \approx 0.4 \times 0.1 \times 0.02=0.0008 \mathrm{~mm}^{3} \mathrm{~s}^{-1}$, where $L_{1}$ is the half-width of the groove. This volume flow (per unit depth) actually leaves in the direction perpendicular to the plane, but in the 2-dimensional model it can be modeled as a drain in the computational cells at the lower boundary, or simply as an outflow in the plane there.

Overall continuity for the cross section yields an estimate for the flow into the computational domain from above, $Q_{0}=U_{0} L_{0} D=7 U_{i} L_{i} D+U_{1} L_{1} L_{2}=7 \times 0.014+$ $0.0008=0.0988 \mathrm{~mm}^{3} \mathrm{~s}^{-1}$. Since $L_{0} \approx 0.3 \mathrm{~mm}$, the approach velocity is ca. $U_{0}=0.33 \mathrm{~mm} \mathrm{~s}^{-1}$. Accordingly, ca. $0.0008 / 0.0988=0.8 \%\left(Q_{1} / Q_{0}\right)$ of the flow entering the gill leaves by flowing through the principal filament groove into the dorsal groove, while the other 99.2\% leaves through the interfilamental canals. Flow driven perpendicular to the plane by frontal cilia is ignored on the assumption that what enters the computational plane from one side exits through the other side.

Fig. 13A shows computed streamlines for the 2-dimensional model described above for the approximate geometry of Chlamys varia in Fig. 1. The closeness of streamlines is a measure of the magnitude of local velocity, which is illustrated by the corresponding velocity vector plot of Fig. 13B. The highest velocities occur along the centerline, reaching values of $\sim 2.5$ times that at the inlet to the funnel between 2 plicate gill crests, as shown in Fig. 14.

As seen from the streamline plot, the incoming flow is being squeezed into the central part far down in between the 2 plicate gill crests. This is due in part to the area reduction between the 2 plicate gill crests and in part to the flows that enter normal to interfilamental canals. The predicted increase in flow velocity between the plicate gill crests is clearly reflected in the acceleration of particles approaching the gill surface. Only particles in the stagnant central current may be captured directly in the principal filament groove; all other particles closely follow the water flowing towards the interfilamental canal inlets into which, however, the particles (probably by the action of prolaterofrontal cilia beating against the interfilamental through-current) are prevented from entering. The turning away of particles along with the downwarddirected main current in the plicate gill crest (Fig. 13A) results in a series of 'particle jumps' from the crest down into the principal-filament groove (Fig. 3).

Second, to illustrate the flow pattern at the entrance to the interfilamental canals, we consider the 2-dimensional flow in a section covering 2 canals including half 


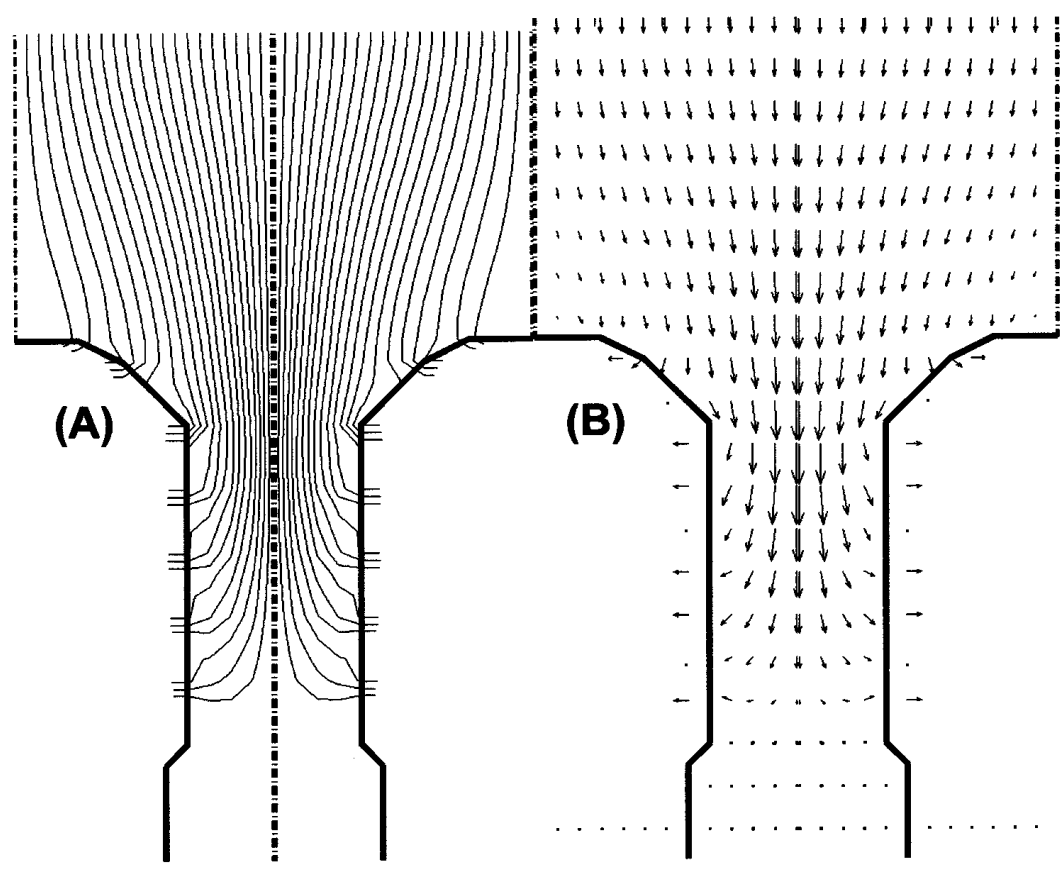

Fig. 13. (A) Computed streamlines and (B) velocity vector plot for 2-dimensional model of flow into funnel between 2 plicate gill crests of Chlamys varia. Model assumes that $99.2 \%$ of flow is drawn into 7 interfilamental canals on each side, while the remaining $0.8 \%$ leaves at bottom, which simulates the dorsally directed flow driven by frontal cilia on the principal filament
In the absence of a pro-laterofrontal cilium, Fig. 16A shows how the flow approaching an interfilamental canal is contracting but aligning itself to enter in the direction of the axis of the canal. However, in the presence of 1 prolaterofrontal cilium in active beat at the upper canal, Fig. 16B shows a significant distortion of the incoming flow being driven towards the filament front. For the case of straight inflow, the use of periodic boundary conditions at the upper and lower boundary simulates a repeated pattern of a row of filaments. Other patterns of beat have been studied. The main conclusion is that a pro-laterofrontal cilium during an active beat introduces significant flow disturbances that may be expected also to interact with the flow generated by the lateral cilia and the frontal cilia (not modeled). Although not de facto demonstrated by the present simulations, it is likely that such disturbances and interactions play an important role in turning away particles at the entrance to the interfilamental canals, an ordinary filament on each side (Fig. 15). Since the mean velocity in interfilamental canals has been established to be $U_{i}=0.35 \mathrm{~mm} \mathrm{~s}^{-1}$ and since the upstream area is twice as large, we specify a uniform incoming flow velocity of $U_{i 0} \approx 0.17 \mathrm{~mm} \mathrm{~s}^{-1}$ either at the left boundary for straight inflow or at the upper boundary for side inflow of the same volume flow. Thus, the lateral cilia that actually drive the flow are not modelled, nor are the frontal cilia, which would drive some flow both into and out of the plane modelled. The 2 cases mentioned represent the conditions near the top and between the 2 plicate gill crests, respectively (cf. Fig. 12). The resulting streamlines and superposed velocity vectors are shown in Fig. 16 for 2 cases: (1) no pro-laterofrontal cilia and (2) 1 pro-laterofrontal cilia (plfc-3) in its active beat at $45^{\circ}$. The tip speed during active beat is estimated to be $U_{\text {tip }} \approx 1 \mathrm{~mm} \mathrm{~s}^{-1}$, assuming a length of $L_{\text {plfc }}=0.012 \mathrm{~mm}$, a frequency of $f=10 \mathrm{~Hz}$, the duration of a $90^{\circ}$ active beat being $20 \%$ of full time period of beat $T=1 / f=0.1$ s, i.e. $U_{\text {tip }}=2 \pi L_{\text {plfc }} /(4 \times 0.2 / f)$ $=2 \pi \times 0.012 /(4 \times 0.2 / 10)=0.94 \mathrm{~mm} \mathrm{~s}^{-1}$. It should be noted that for a particle (following the fluid) to travel the $0.12 \mathrm{~mm}$ from the left boundary of Fig. 16A (left) to the position of filaments at a speed between $U_{i 0}$ and $U_{i}$ (say at $0.2 \mathrm{~mm} \mathrm{~s}^{-1}$ ) would take approx. 6 periods of cilium beat, so if the cilia beat and create disturbances, it is likely that they would be felt by most particles. leading to the observed 'particle jumps'. Note that during the passive return beat, which moves with the flow at ca. $25 \%$ of the tip speed $\left(\approx 0.25 \mathrm{~mm} \mathrm{~s}^{-1}\right)$, distortions are negligible, yielding almost the patterns of no prolaterofrontal cilia. This is shown in Fig. 17, giving instantaneous flows for plfc-3 (Fig. 15) at positions $0^{\circ}$ and $90^{\circ}$ during a passive beat, at rest, and at active

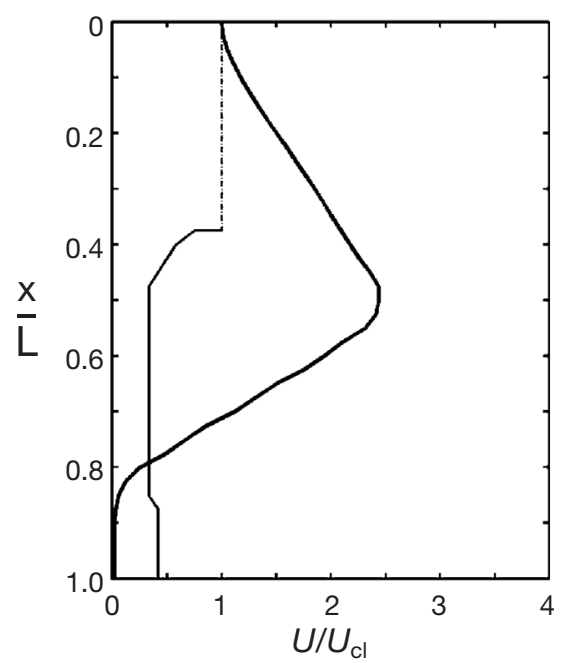

Fig. 14. Computed centerline velocity midway between 2 plicate gill crests vs. position (heavy line), where position is indicated by contour of computational domain (thin line and dashed line). $x$ : distance from inlet flow; $L$ : length; $U$ : centerline velocity; $U_{\mathrm{cl}}$ : centerline velocity at inflow 


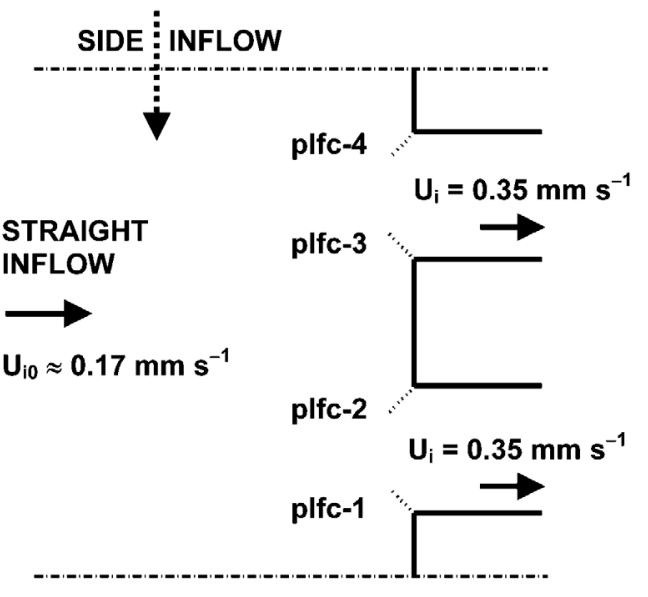

Fig. 15. Geometry of computational model of flow into 2 interfilamental canals. Four pro-laterofrontal cilia (plfc-1 to plfc-4) shown in $45^{\circ}$ positions can induce velocities corresponding to an active or passive beat, respectively, between $0^{\circ}$ and $90^{\circ}$. In the case of straight inflow, upper and lower boundaries are periodic. In the alternative case of side inflow, left and lower boundaries are lines of symmetry (as in Fig. 16). $U_{i}$ : mean velocity in the interfilament canals; $U_{i 0}$ : uniform incoming flow velocity beat. Note the region of recirculation shown in the lower left of Fig. 17C, a phenomenon that is much stronger when the 2 cilia on a filament (e.g. plfc-2 and plfc-3) are both beating actively. Fig. 18 demonstrates that disturbances created by pro-laterofrontal cilia during an active beat can reach far into the plicate gillcrest funnel. The flow calculations cover the symmetric half of the narrow funnel, including outflow through 2 interfilamental canals, Canals 4 and 5 (Fig. 12). The incoming flow at the upper boundary equals $\sim 4$ times that leaving through 1 canal, and the outgoing flow at the lower boundary equals what should leave through Canals 6 and 7 and in the interplicate groove.

It should be stressed that a 2-dimensional model of a moving cilium implies a moving impermeable plane perpendicular to the computational plane, which would only be a realistic approximation provided several closely spaced adjacent cilia were in phase during a beat. If not, the resulting flow disturbances would be less. On the other hand, the use of a steady solution to represent the instantaneous flow of an unsteady problem due to an imbedded moving object (pro-laterofrontal cilia) does not represent any approximation

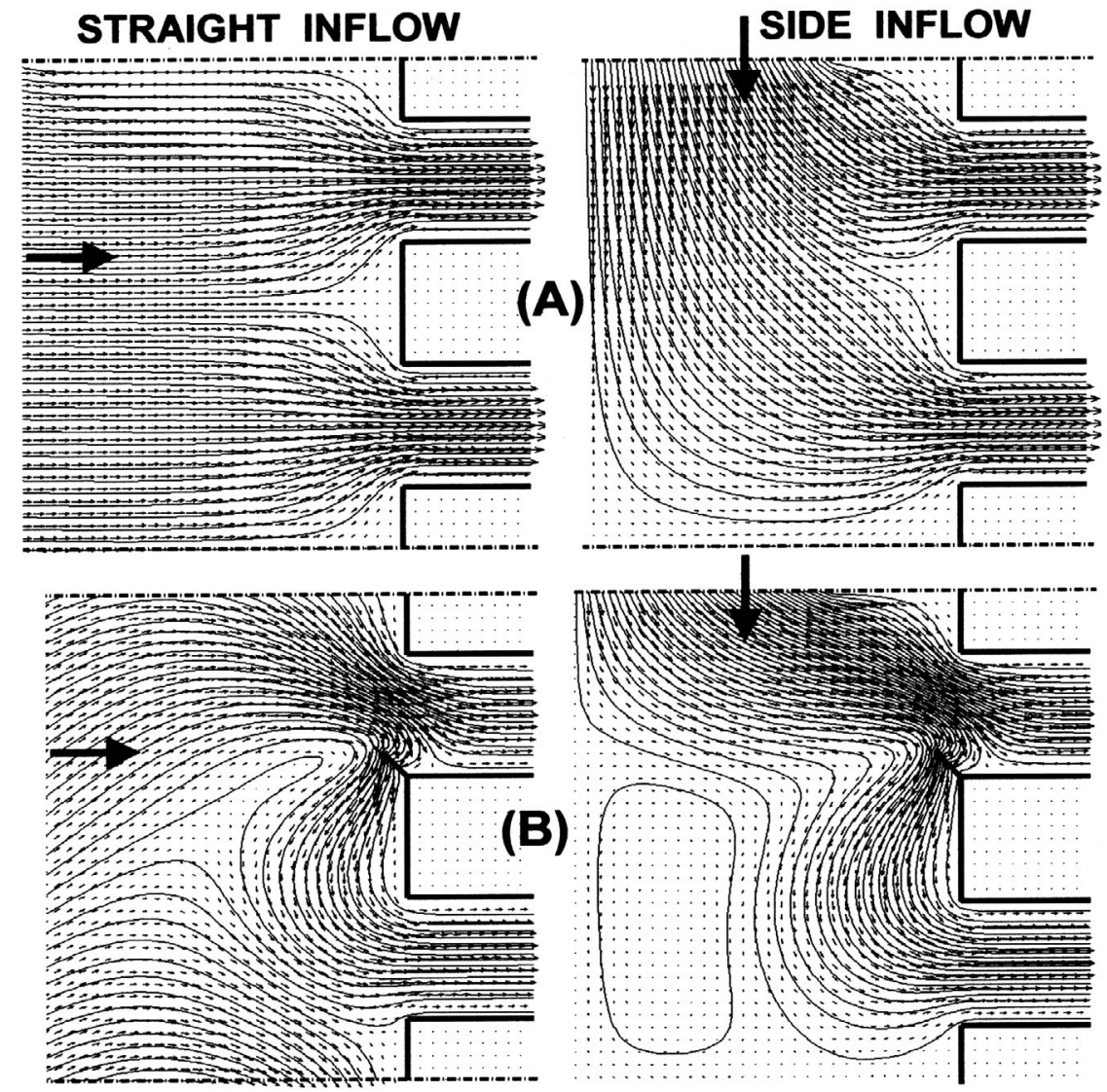

Fig. 16. Computed streamlines and velocity vectors for 2-dimensional model of inflow from the left (straight inflow) and from the top (side inflow) into 2 interfilamental canals. (A) No pro-laterofrontal cilia (plfc), (B): plfc-3 at $45^{\circ}$ during an active beat where the tip speed $U_{\text {tip }}=1 \mathrm{~mm} \mathrm{~s}^{-1}$ 


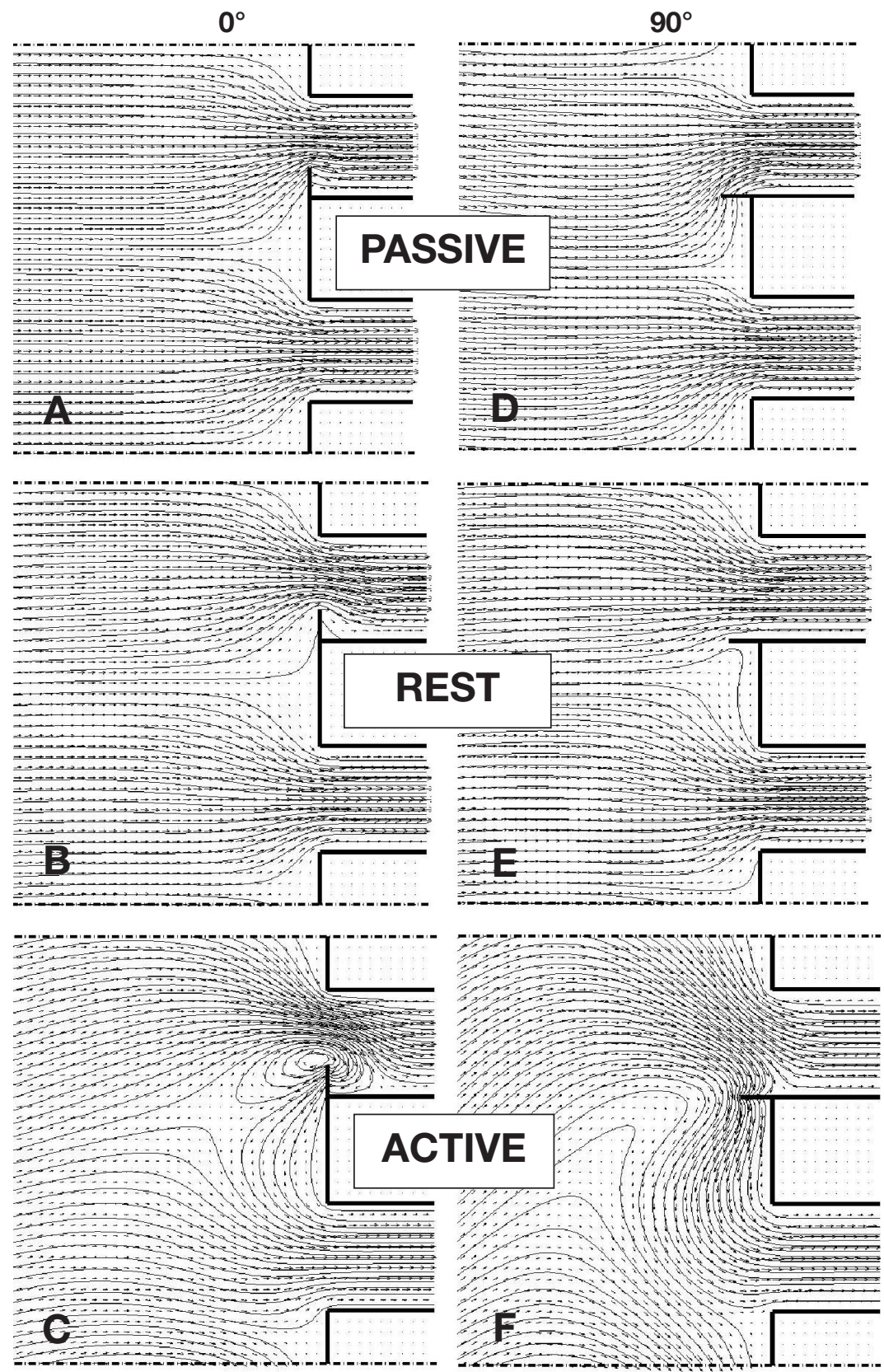

Fig. 17. (A-C) Pro-laterofrontal cilia (plfc)-3 during the position $0^{\circ}$ at passive, resting and active beat. (D-F) plfc-3 during the position $90^{\circ}$ during the passive, rest and active beat. (Computational domain extends another $0.080 \mathrm{~mm}$ upstream of that shown)

as long as inertia is negligible, i.e. for a creeping flow at very low values of the Reynolds number (cf. for the beating cilium, $\operatorname{Re}=L_{\text {plfc }} U_{\text {tip }} / \nu=12 \times 10^{-6} \times 0.001 /$ $10^{-6} \approx 10^{-3}$, where $v$ denotes the kinematic viscosity). Also, the model assumes constant nominal volume flows to each interfilamental canal, irrespective of the degree of upstream disturbances. In reality, increased 'system' resistance due to upstream disturbances would likely reduce flow to a given canal according to the pump characteristic (cf. Riisgård \& Larsen 1995).

\section{DISCUSSION}

To improve our understanding of the feeding processes of scallops having pro-laterofrontal cilia the present study has provided new experimental data on the paths and velocities of particles (Figs. 4 \& 5) as well as computational results of selected local flow patterns (Figs. 13 to 18). But the gill structures of Palliolium furtivus were also studied by SEM to show tracts of lateral cilia organized in 'frozen' metachronic waves and 
one row of pro-laterofrontal cilia between the lateral cilia and frontal cilia (Fig. 2), showing the width of both ordinary filaments and an interfilamental canal of $\sim 40 \mu \mathrm{m}$. In addition, the filtration rates and the effect of HT-5 on isolated gill filaments were studied to provide quantitative data on velocities needed for the computational flow model and for making independent observations which can be compared with model predictions.

An important parameter in the present flow analysis is the mean velocity in the interfilamental canals, $U_{i}$. Therefore, particular care was taken to make precise filtration rate measurements on undisturbed scallops exploiting their pumping capacity. From Figs. 10 \& 11 it is seen that maximum filtration rate is not obtained until approx. 1 to $2 \mathrm{~h}$ after the first algal addition, in agreement with a recent observation on scallops (Riisgård 2004) and earlier observations in 3 species of filter-feeding bivalves (Riisgård et al. 2003). For Aequipecten opercularis, filtration rates per $\mathrm{cm}$ length of lateral ciliary band (Table 1) provided the estimate $U_{i}=0.35 \mathrm{~mm} \mathrm{~s}^{-1}$.

Other velocities and particle paths were determined by video-microscope observations on actively feeding specimens with the adductor muscle cut (Figs. 3 to 5), while detailed motion related to particle capture was observed on isolated gill preparations. For this reason the present work has quantified the effect of HT-5 on beat frequency, wavelength, and wave speed of isolated gill filaments of Aequipecten opercularis, and it is shown that stimulation of the lateral cilia with $10^{-5} \mathrm{M}$ 5 -HT results in a beat frequency of $\sim 20 \mathrm{~Hz}$ (Fig. 7). The results also show that HT-5 is highly potent in stimulating lateral cilia activity. According to a simple analysis of the lateral cilia pump made by Riisgård et al. (2000), the mean water velocity $\left(u_{\mathrm{m}}\right)$ may be determined as $u_{\mathrm{m}}=0.5 u_{\text {tip }}\left(T_{\mathrm{a}} / T\right)$, where $T$ is the full period of a beat and $T_{\mathrm{a}}$ is the period of the active beat of lateral cilia of length $L$ through angle $\theta$ (degrees), giving the tip velocity $u_{\text {tip }}=(\theta / 360) 2 \pi L / T_{\mathrm{a}}$. Using $L=15 \mu \mathrm{m}, 1 / T=$ $20 \mathrm{~Hz}, T_{\mathrm{a}}=0.2 T$, and $\theta=150^{\circ}$ gives $u_{\text {tip }}=3.9 \mathrm{~mm} \mathrm{~s}^{-1}$ and $u_{\mathrm{m}}=0.4 \mathrm{~mm} \mathrm{~s}^{-1}$. These values are in general agreement with the particle velocities shown in Figs. 8 \& 9 and the estimated mean water velocity $U_{i}=$ $0.35 \mathrm{~mm} \mathrm{~s}^{-1}$ in the interfilamental canals.

Ward et al. (1993) ave suggested that endoscopic techniques may be used to observe feeding mechanisms in bivalves, thus eliminating anomalies caused by surgery and excessive manipulation. Endoscopic video observations made by Beninger et al. (1992, 2004) and Ward et al. (1998) have provided new information on particles approaching the gill and particle transport and selection in intact bivalves. Although the interpretations of observed processes of particle capture may differ, cf. comment by Riisgård \& Larsen (2000) on endoscopic video observations made by Ward et al. (1998), many observations are identical and there are no indications of disturbed flow patterns in the present work compared to earlier observations made by endoscopy.

Regarding the flows associated with the feeding process, it is well established (Jørgensen 1990) that the incurrent far-field flow is parallel to the gill filaments, proceeding dorsally while being deflected into the funnels between plicate gill crests towards the interplicate grooves of principal filaments. The far-field currents are created by the ciliated frontal surfaces of both principal filaments and ordinary filaments. The flow into funnels is driven by the lateral cilia pumps of ordinary filaments and frontal cilia of principal filaments. The paths of particles approaching the gill surface shown in Figs. 4 \& 5 were always curved in the direction normal to the gill frontal surface and not inclined at a low angle $\left(\sim 30^{\circ}\right)$ as reported by Ward et al. (1998). Such curved particle paths were to be expected because of the parallel arrangement of the lateral cilia pump on gill filaments, and the computed flow patterns in Figs. 13, $16 \& 18$ (without a simulated active beat of pro-laterofrontal cilia) show similar paths despite the confinement and acceleration of the flow in the narrow crest-funnel, which directs the flow parallel to the filament fronts. Note that the present videomicroscope observations of particles approaching the gill have been made on scallops with their adductor muscle cut, and the possibility cannot be excluded that the flow patterns and particle movements observed in the surgically altered scallops could differ from patterns that might be observed in undisturbed and maximally pumping animals. However, earlier video observations made on the flat gill of an intact and actively feeding blue mussel by Riisgård \& Larsen (2000) showed similar particle paths. Here, the flat gills could clearly be seen behind the gaping valves when the mussel was fixed on the lateral side in an observation chamber and video recordings were obtained through the inhalant opening.

The modelled velocity profiles of water flow at different depths of the plicate gill crest funnel are approximately parabolic with highest velocity in the middle (Fig. 13), and this velocity attains its largest value $\left(2.5 \times U_{0}\right)$ somewhat down in the crest funnel (cf. Figs. 12 \& 14). According to Riisgård \& Seerup (2003) and Jørgensen et al. (1990), the filtration rate of a ciliary filter-feeding bivalve at $20^{\circ} \mathrm{C}$ is ca. 1.8 times higher than the filtration rate measured at $5^{\circ} \mathrm{C}$. Therefore, according to the present flow analysis, which is based on an inflow velocity of $U_{0}=0.33 \mathrm{~mm} \mathrm{~s}^{-1}$ (according to a mean velocity of $U_{i}=0.35 \mathrm{~mm} \mathrm{~s}^{-1}$ in interfilamental canals estimated on basis of filtration rates measured at $5^{\circ} \mathrm{C}$ ) the predicted maximum velocity of particles entering the plicate gill crest funnel near the centre of the crest funnel at $20^{\circ} \mathrm{C}$ is: $2.5 \times U_{0} \times$ 

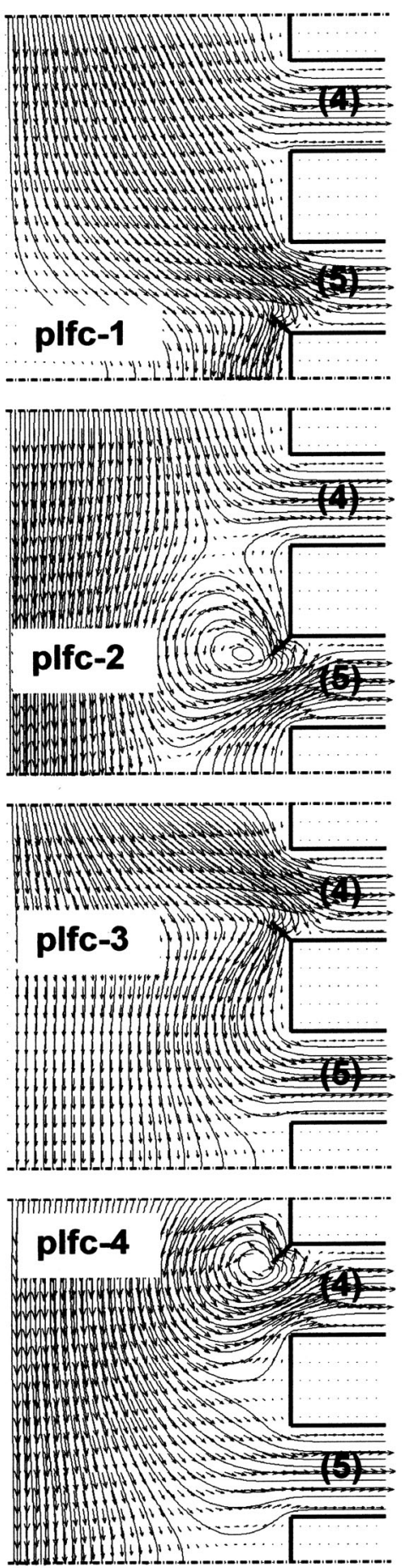

Fig. 18. Computed streamlines and velocity vectors for 2-dimensional model of flow in the symmetric half of the funnel region including interfilamental Canals 4 and 5 (see Fig. 12). Top to bottom: One pro-laterofrontal cilium (plfc- 1 to plfc- 4 ) at $45^{\circ}$ during an active beat where the tip speed $U_{\text {tip }}=1 \mathrm{~mm} \mathrm{~s}^{-1}$. (Note: An animation of computed gill flow related to Fig. 18 has been placed on the MEPS web page as supplementary material, available at: www.intres.com/articles/suppl/m303p177_animation.avi, together with a supplementary appendix, available at: www.int-res.com/ articles/suppl/m303p177_app.pdf)
$1.8=2.5 \times 0.33 \times 1.8=1.5 \mathrm{~mm} \mathrm{~s}^{-1}$, in good agreement with the experimental observations shown in Figs. 4 \& 5 .

The plicate gill crests of ordinary filaments are likely functional, accelerating the core flow towards the principal filament. Also, there are likely favourable interactions between the through flow and the flow generated by the pro-laterofrontal cilia, the frontal cilia and the water-pumping lateral cilia on ordinary filaments, although the nature of these interactions has not been identified in detail. However, beating of the pro-laterofrontal cilia creates significant interaction with the downflow, reaching well into it, as demonstrated by the present calculations (Fig. 18), so this effect of pro-laterofrontal cilia cannot be dismissed as suggested by Owen \& McCrae (1976). The calculations also show local regions of recirculating flow associated with the active beat of 'upstream' pro-laterofrontal cilia (Fig. 18, plfc-2 and plfc-4), but not with 'downstream' pro-laterofrontal cilia, referring to the direction of downflow. Ward et al. (1998, Fig. 5 therein) suggest that pro-laterofrontal cilia (or cirri) may produce recirculation regions (vortices) both up- and downstream and that 2 such vortices would tend to block the outflow to an interfilamental canal. As mentioned, the results of the present flow simulations, e.g. in Fig. 18, have their limitations and should be taken with some reservation, since they are 2-dimensional and are based on specified and constant volume flows to each interfilamental canal. Two-dimensionality is approached only if many adjacent pro-laterofrontal cilia beat in phase, and pro-laterofrontal cilia and the local flows they generate during active beats represent an increased flow resistance felt by the lateral cilia-pumps, which probably will reduce the volume flow periodically to any given interfilamental canal. Nevertheless, pro-laterofrontal cilia likely play a role in transferring incoming particles either to frontal cilia bands or back into the strong downflow, leading to the observed particles 'jumps' downward across the ordinary filaments to eventually land on the principal filament.

The idea that unsteady 3-dimensional flows generated by various cilia systems may play a crucial role in the capture process has been suggested several times (e.g. Jørgensen 1981, 1982, 1990, Riisgård et al. 1996) but still needs to be verified in detail. The present work has added to the overall bank of knowledge, but it also suggests that further observational and theoretical support is needed to fully understand the particlecapture mechanism in scallops.

Acknowledgements. Thanks to the Marine Biological Laboratory, Helsingør, for supply of scallops, to N. Krogh for technical assistance with the figures, and to C. Kittner for technical laboratory assistance, especially for conducting the meticulous 5-HT and filtration rate experiments. We highly appreciate the constructive criticism made by 5 reviewers who found that our work merited 25 pages of comments which have greatly improved the 
manuscript. In particular, P. Beninger and E. Ward, who revealed their reviewer identity, are cordially acknowledged for their many constructive comments. This study has been supported by a grant from the Danish Natural Science Research Council (Grant No. 21-03-0481 to H.U.R.).

\section{LITERATURE CITED}

Aiello E (1960) Factors affecting ciliary activity on the gill of the mussel Mytilus edulis. Physiol Zool 33:20-135

Beninger PG (2000) A critique of premises and methods in a recent study of particle capture mechanisms in bivalves. Limnol Oceanogr 45:1196-1199

Beninger PG, Le Pennec M, Salaün M (1988) New observations of the gills of Placopecten magellanicus (Mollusca: Bivalvia), and implications for nutrition. Mar Biol 98:61-70

Beninger PG, Ward JE, MacDonald BA, Thompson RJ (1992) Gill function and particle transport in Placopecten magellanicus (Mollusca: Bivalvia) as revealed using video endoscopy. Mar Biol 114:281-288

Beninger PG, Decottignies P, Rincé Y (2004) Localization of qualitative particle selection sites in the heterohabdic filibranch Pecten maximus (Bivalvia: Pectinidae). Mar Ecol Prog Ser 275: 163-173

Dral ADG (1967) The movement of the latero-frontal cilia and mechanism orparticle retention in the mussel (Mytilus edulis L.). Neth J Sea Res 3:391-422

Gibbons IR (1961) The relationship between the fine structure and direction of beat in gill cilia of a lamellibranch mollusc. J Biophys Biochem Cytol 11:179-205

Jørgensen CB (1975) On gill function in the mussel Mytilus edulis L. Ophelia 13:187-232

Jørgensen CB (1976) Comparative studies on the function of gills in suspension feeding bivalves, with special reference to effects of serotonin. Biol Bull (Woods Hole) 151:331-343

Jørgensen CB (1981) A hydromechanical principle for particle retention in Mytilus edulis and other ciliary suspension feeders. Mar Biol 61:277-282

Jørgensen CB (1982) Fluid mechanics of the mussel gill: the lateral cilia. Mar Biol 70:275-281

Jørgensen CB (1983) Fluid mechanical aspects of suspension feeding. Mar Ecol Prog Ser 11:89-103

Jørgensen CB (1990) Bivalve filter feeding: hydrodynamics, bioenergetics, physiology and ecology. Olsen \& Olsen, Fredensborg

Jørgensen CB (1996) Bivalve filter feeding revisted. Mar Ecol Prog Ser 142:287-302

Jørgensen CB, Kiørboe T, Møhlenberg F, Riisgård HU (1984) Ciliary and mucus net filter feeding, with special reference to fluid mechanical characteristics. Mar Ecol Prog Ser 15:283-292

Jørgensen CB, Famme P, Kristensen HS, Larsen PS (1986) The bivalve pump. Mar Ecol Prog Ser 34:69-77

Jørgensen CB, Larsen PS, Riisgård HU (1990) Effects of temperature on the mussel pump. Mar Ecol Prog Ser 33:89-97

McHenery JG, Birkbeck TK (1985) Uptake and processing of cultured microorganisms by bivalves. J Exp Mar Biol Ecol 90: 145-163

Møhlenberg F, Riisgård HU (1978) Efficiency of particle retention in 13 species of suspension-reeding bivalves. Ophelia 17: $239-246$

Moore HJ (1971) The structure of the latero-frontal cirri on the gills of certain lamellibranch molluscs and their role in suspension feeding. Mar Biol 11:23-27

Nelson TC (1960) The feeding mechanism of the oyster. II. On the gills and palps of Ostrea edulis, Crassostrea virginica and C. angulata. J Morphol 107:163-203

Nielsen NF, Larsen PS, Riisgård HU, Jørgensen CB (1993) Fluid motion and particle retention in the gill of Mytilus edulis: video recordings and numerical modelling. Mar Biol 116:61-71

Nørrevang A, Wingstrand KG (1970) On the occurrence and structure of choanocyte-like cells in some echinoderms. Acta Zool (Stockh) 51:249-270

Owen G (1974) Studies on the of Mytilus edulis: the eu-laterofrontal cirri. Proc R Soc Lond B 187:83-91

Owen O, McCrae JM (1976) Further studies on the latero-frontal tract of bivalves. Proc R Soc Lond B 194:527-544

Riisgård HU (1988) Efficiency of particle retention and filtration rate in 6 species of Northeast American bivalves. Mar Ecol Prog Ser 45:217-223

Riisgård HU (2004) Intercalibration of methods for measurement of bivalve filtration rates - a turning point. Mar Ecol Prog Ser 276:307-308

Riisgård HU, Larsen PS (1995) Filter-feeding in marine macroinvertebrates: pump characteristics, modelling and energy cost. Biol Rev Camb Phil Soc 70:67-106

Riisgård HU, Larsen PS (2000) A comment on experimental techniques for studying particle capture in filter-feeding bivalves. Limnol Oceanogr 45:1192-1195

Riisgård HU, Larsen PS (2001) Ciliary filter feeding and bio-fluid mechanics - present understanding and unsolved problems. Limnol Oceanogr 46:882-891

Riisgård HU, Seerup DF (2003) Filtration rates in soft clam, Mya arenaria: effects of temperature and body size. Sarsia 88: $425-428$

Riisgård HU, Larsen PS, Nielsen NF (1996) Particle capture in the mussel Mytilus edulis: the role of latero-frontal cirri. Mar Biol 127:259-266

Riisgård HU, Nielsen C, Larsen PS (2000) Downstream collecting in ciliary suspension feeders: the catch-up principle. Mar Ecol Prog Ser 207:33-51

Riisgård HU, Kittner C, Seerup DF (2003) Regulation of opening state and filtration rate in filter-feeding bivalves (Cardium edule, Mytilus edulis, Mya arenaria) in response to low algal concentration. J Exp Mar Biol Ecol 284:105-127

Silverman H, Achberger EC, Lynn JW, Dietz TH (1995) Filtration and utilization of laboratory-cultured bacteria by Dreissena polymorpha, Corbicula fluminea, and Carunculina texasensis. Biol Bull (Woods Hole) 189:308-319

Silverman H, Lynn JW, Dietz TH (1996) Particle capture by the gills of Dreissena polymorpha: structure and function of laterofrontal cirri. Biol Bull (Woods Hole) 191:42-54

Silverman H, Lynn JW, Beninger PG, Dietz TH (1999) The role of latero-frontal cirri in particle capture by the gills of Mytilus edulis. Biol Bull (Woods Hole) 197:368-376

Silverman H, Lynn JW, Dietz TH (2000) In vitro studies of particle capture and transport in suspension-feeding bivalves. Limnol Oceanogr 45:1199-1203

Silvester NR, Sleigh MA (1984) Hydrodynamic aspects of particle capture by Mytilus. J Mar Biol Assoc UK 64:859-897

Vahl O (1973) Efficiency of particle retention in Chlamys islandica (O.F. Müller). Astarte 6:21-25

Ward JE (1996) Biodynamics of suspension-feeding in adult bivalve molluscs: particle capture, processing, and fate. Invertebr Biol 115:218-231

Ward JE, MacDonald BA, Thompson RJ, Beninger PG (1993) Mechanisms of suspension-feeding in bivalves: resolution of currrent controversies by means of endoscopy. Limnol Oceanogr 38:265-272

Ward JE, Sanford LP, Newell RIE, MacDonald BA (1998) A new explanation of particle capture in suspension-feeding bivalve molluscs. Limnol Oceanogr 43:741-752

Ward JE, Sanford LP, Newell RIE, MacDonald BA (2000) The utility of in vivo observations for describing particle capture processes in suspension-feeding bivalve molluscs. Limnol Oceanogr 45:1203-1210 
Appendix 1. Two-dimensional, incompressible, creeping flow

The velocity distribution $(u, v)$ of a 2-dimensional flow in the $x, y$-plane may be expressed in terms of the distributions of stream function $\psi$ and vorticity $\omega$, defined by

$$
u=\partial \psi / \partial y, v=-\partial \psi / \partial x ; \omega=\partial v / \partial x-\partial u / \partial y
$$

The definition of $\psi$ is seen to satisfy conservation of mass (continuity), $\partial u / \partial x+\partial v / \partial y=0$, and eliminating $u$ and $v$ from Eq. (1) yields

$$
\partial^{2} \psi / \partial x^{2}+\partial^{2} \psi / \partial y^{2}+\omega=0
$$

which is 1 of 2 equations governing $\psi$ and $\omega$, while the other one is derived from the momentum equations, which in the limit of creeping flow at vanishing values of the Reynolds number reduces to

$$
\partial^{2} \omega / \partial x^{2}+\partial^{2} \omega / \partial y^{2}=0
$$

Since this formulation ignores inertia, Eq. (3) is equally valid for steady and unsteady flows. This means that the flow instantaneously adjusts to any change, such as an unsteady boundary condition of a moving cilium, and a sequence of solutions at slightly different speeds or positions would provide a movie of the unsteady flow.

The numerical solution to the discretized forms of Eqs. (2) \& (3) subject to boundary conditions yields $\psi, \omega$, hence streamlines $\psi=$ constant, while velocity vectors $(u, v)$ are obtained from Eq. (1). For the present model problems, boundary conditions on $\psi$ are readily specified from required volume flows. In Fig. 12, for example, setting $\psi=0$ at the left symmetry line (chosen as $x$-axis) and $\psi=U_{0} y$ at the inlet (chosen as $y$-axis), corresponding to $u=U_{0}$, gives $\psi=\psi_{0}=U_{0} L_{0}$ at the right symmetry line. This value is successively reduced by the volume flow leaving at each canal outlet along the contour of the plicate gill crest. The remaining volume flow will leave at the bottom, where the Neumann condition, $\partial \psi / \partial x=0$, is specified. Consider finally a straight cilium of length $L_{\text {plfc }}$ beating with instantaneous velocity $u=$ $U_{\text {tip }} \tilde{Y} / L_{\text {plfc, }}$ where $U_{\text {tip }}$ is the tip speed and $\tilde{Y}$ the local coordinate such that the root at $\tilde{y}=0$ is located at a boundary point where $\psi=\psi_{\text {root }}$. Thus, according to Eq. (1), the stream function is simply specified along the cilium as

$$
\psi(\tilde{\mathrm{y}})=\psi_{\text {root }}+0.5 U_{\text {tip }} \tilde{\mathrm{Y}}^{2} / L_{\text {plfc }}
$$

Next, the condition for vorticity on a rigid boundary along an $x$-axis is derived from a series expansion of $\psi(x, y)$ from a boundary point $\mathrm{W}$ to a near-wall node $\mathrm{P}$ in the $y$-direction and a nearby node in the $x$-direction, yielding the approximation for $\omega_{\mathrm{W}}$ on the boundary

$$
\omega_{\mathrm{W}} \approx-2\left(\psi_{\mathrm{P}}-\psi_{\mathrm{W}}\right) / \Delta^{2}+2\left(U_{\mathrm{W}}-V_{\mathrm{W}}\right) / \Delta
$$

where $U_{\mathrm{W}}$ and $V_{\mathrm{W}}$ denote the velocity components of the boundary along and perpendicular to it, respectively, and $\Delta$ denotes the distance between nodes in an equidistant Cartesian mesh. For a wall at rest, the last term in Eq. (5) vanishes, leaving the usual no-slip condition of first order. But for the beating cilium considered above, $V_{\mathrm{W}}=0$ and $U_{\mathrm{W}}=U_{\text {tip }} \tilde{Y} / L_{\mathrm{plfc}}$, and if the boundary consists of a single line of nodes, $\psi_{\mathrm{P}}$ is taken as the mean value of the near-wall nodes to the 2 sides of the wall point.

Along lines of symmetry, the slip condition is equivalent to a Neumann condition in the direction normal to the boundary, $\partial \omega / \partial n=0$. At the exit the assumption of no further change implies a Neumann condition in the direction of flow, $\partial \omega / \partial x=0$. The inlet condition of uniform parallel flow, i.e. $u(y)=$ constant and $v=0$, hence $\omega=0$ according to Eq. (1), is appropriate if the inlet is sufficiently far upstream of disturbances that upstream diffusion of vorticity is negligible 